\title{
Contributing to the cultural ecosystem services and human wellbeing debate: a case study application on indicators and linkages
}

\author{
Peter Waweru Wangai ${ }_{1,2}{ }^{*}$, Benjamin Burkhard 3,4 , Marion Kruse 1, Felix Müller 1 \\ 1 Kiel University, Institute for Natural Resource Conservation, Olshausenstr. 40, 24098 Kiel, Germany \\ 2 Kenyatta University, Department of Environmental Studies \& Community Development, P.O. Box 43844-00100 Nairobi, Kenya \\ 3 Leibniz Universität Hannover, Institute of Physical Geography and Landscape Ecology, Schneiderberg 50, 30167 Hannover, \\ Germany \\ 4 Leibniz Centre for Agricultural Landscape Research ZALF, Eberswalder Str. 84; 15374 Müncheberg, Germany
}

\begin{abstract}
Inadequacies in the indication of cultural ecosystem services (CES) are a hindrance in assessing their comprehensive impacts on human wellbeing. Similarly, uncertainties about the quantity and quality of CES, in real time and space, have hampered the ability of resource managers to precisely take responsive management actions. The aim of the study is to demonstrate, how CES indicators can be identified and qualified in order to link CES to human wellbeing, and to integrate them into the 'ecosystem services cascade' and the Driver-Pressure-State-Impact-Response (DPSIR) models. A case study methodology is applied at the Nairobi-Kiambu (Kenya) peri-urban area. Primary data on CES was collected in the case study through survey, field observations and matrix tables. Secondary data originates from literature analysis. Results show that the participatory identification of CES and human wellbeing indicators could improve their transparency and comprehensibility. The environmental policy formulation and implementation processes have been demonstrated. The tripartite framework of CES-human wellbeing-DPSIR has demonstrated more linkages and feedbacks than initially indicated in the cascade model. For policy formulation and implementation, appropriate communication of results is mandatory. This is illustrated by a terminology that enables the transfer of scientific messages to stakeholders, especially for the local people. The conclusion indicates the importance of consistency in qualifying CES and human wellbeing indicators even at this time of urgency to bridge the gaps existing in CES and human wellbeing research.
\end{abstract}

\section{Keywords:}

Indicator selection, Interviews, Kenya, DPSIR-framework, Human wellbeing

Submitted: 12 October 2016 / Accepted in revised form: 20 March 2017 / Published: 29 March 2017

*Corresponding author. Email: pwangai@ecology.uni-kiel.de

(C) The Authors. 2017. Landscape Online. This is an Open Access article distributed under the terms of the Creative Commons Attribution License (http://creativecommons.org/licenses/by/4.0), which permits unrestricted use, distribution, and reproduction in any medium, provided the original work is properly cited. 
Highlights

- Identifying and qualifying indicators of cultural ecosystem services and human wellbeing.

- Integrating cultural ecosystem services and human wellbeing into the ecosystem services cascade and DPSIR models.

- Closing loops and links between human wellbeing, policy formulation and policy implementation.

- Simplifying inter-stakeholder communication without distorting the scientific message.

- Case study application in Kenya.

\section{Introduction}

C ultural ecosystem services (CES) are defined as the intangible benefits of ecosystems to people (MA 2005). Besides regulating and provisioning ecosystem services, CES are one category of ecosystem services (ES) (CICES, http://cices.eu/, 24.02.2017). ES are defined as the "contributions of ecosystem structure and function - in combination with other inputs - to human well-being (Burkhard et al. 2014). In order to determine the impact of CES on humans, they need to be linked to the human wellbeing (Turner \& Daily 2008). Unlike CES that are widely defined in literature (MA 2005, Chan et al. 2012; Daniel et al. 2012; Plieninger et al. 2013; La Rosa et al. 2015), attempts to define human wellbeing have remained on a conceptual level in most cases. Wellbeing depends on both material and nonmaterial (intangible) inputs from ecosystems and social interrelations, but most of the human development agendas have discriminatively emphasised on material goods and services (Alkire et al. 2011). This tends to overlook the fact that the quality and quantity of the inputs required for a 'desired wellbeing' are basically constructs of the human mind and depend on the context, an individual, a people, or an institution (Daniel et al. 2012). Nevertheless, the MA (2005) availed five universal constituents of human wellbeing (security, basic material for good life, health, good social relations, freedom of choice and action), which became a platform for assessing the linkages between ES and human wellbeing. The ES framework by the MA could be termed the most dramatic shift from the view that wellbeing is about focusing on the ends only, to a holistic view of linking the ends to the means and understanding the iterative processes that are included (Duraiappah 2002; Abunge et al. 2013). Provisioning, regulating and cultural ES demonstrate direct linkages to human wellbeing. Although there is recognition of varying strength of the linkages, it was not the intention of the MA (2005) to create a hierarchy of importance of the ES categories to wellbeing. Instead, the MA (2005) makes a quick reference to the varying 'potential for mediation' for the three ES (provisioning, regulating and cultural) categories. It emerges that on overall, CES seem to have the lowest 'potential for mediation' and this means that human inputs are limited in generating substitutes for CES.

In ecosystem and environmental sciences, indicators have been defined widely (Müller et al. 2000; Metzger et al. 2006; Müller \& Burkhard 2012). In this paper, we refer to the indicator definition by Kandziora et al. (2013 p. 54), that "indicators are variables which provide aggregated information on certain phenomena and are comprehended as depictions of qualities, quantities, states or interactions that are not directly accessible". The inadequacy (quality and quantity) of CES indicators has hampered research on the linkages between CES and human wellbeing. For example, Hernández-Morcillo et al. (2013) confirm that only $38(11 \%)$ of the total number of ES indicators in the MA report refer to CES. However, the number of CES indicators have increased from 38 in 2005 to 70 in 2012 (Hernández-Morcillo et al. 2013).

In the applications of ES indicators in biodiversity and ES research, CES indicators account for only $6 \%$, which leads to inadequate detection and measurement of 'status and trends' of CES (Feld et al. 2009). Although the statistics may call for a scientific 'quick-fix' aimed at defining new indicators, it should be noted that the quality of indicators is similarly quintessential and should not be compromised in the rush to address the 'quantity gap' in CES indicators. Quality of CES indicators determines the reproducibility, adoptability and extrapolation potential of results in social, cultural, political and economic contexts. 
Müller and Burkhard (2012 p. 26) argue that since ES "can be understood as the direct and indirect contributions of ecosystem structures and functions - in combination with other inputs - to human well-being [...], ES can be nominated as indicators" an argument supported by Kumar et al. (2013). The inter-linkages between ecosystem structures and processes and human wellbeing are demonstrated by the 'ecosystem services cascade' (Haines-Young \& Potschin 2010) and elaborated by the DriverPressure-State-Impact-Response (DPSIR) model (Müller \& Burkhard 2012; Kandziora et al. 2013). The 'ecosystem service cascade' presents a visualized 'production chain' that connects "ecological and biophysical structures and processes on the one hand and elements of human well-being on the other..." (Potschin \& Haines-Young 2011, p. 577). The DPSIR model is a framework to identify and analyse the cause-effect relationships resulting from human-environment interactions (Burkhard \& Müller 2008, Hou et al. 2014, Nassl \& Löffler 2015, Spanò et al. 2017). The two models assist in capturing the human-environment interrelationships that are vital in ensuring sustainability of socio-ecological systems. Based on the scantiness of published CES indicators, this paper is focusing on the development and application of CES indicators as a prerequisite for addressing CES-human wellbeing interlinkages. In order to operationalize this theoretical understanding, Müller \& Burkhard (2012) propose to work with 'comprehensive sets of indicators' in order to ensure appropriate identification and quantification of ES, including their trade-offs and synergies. It is undoubtedly to say that due to the persisting underrepresentation of CES and wellbeing in the ES debate (Gee \& Burkhard 2010; Sagie et al. 2013; La Rosa et al. 2015; Darvill \& Lindo 2015), there is urgency for more comprehensive sets of CES (La Rosa et al. 2015) and human wellbeing indicators. In response to the urgency, Kandziora et al (2013) compiled a list of respective CES indicators. In the "ecosystem service cascade" (Haines-Young \& Potschin 2010 p. 116), human benefits and values are located on the cascade's right hand side (Fig. 1). These ES-based benefits and values influence human wellbeing, which gives meaning to the concept of coupled human-environmental systems (Müller \& Burkhard 2012). Quality of life, which can be described by the constituents of human wellbeing (MA 2005), depends on CES. Moreover,

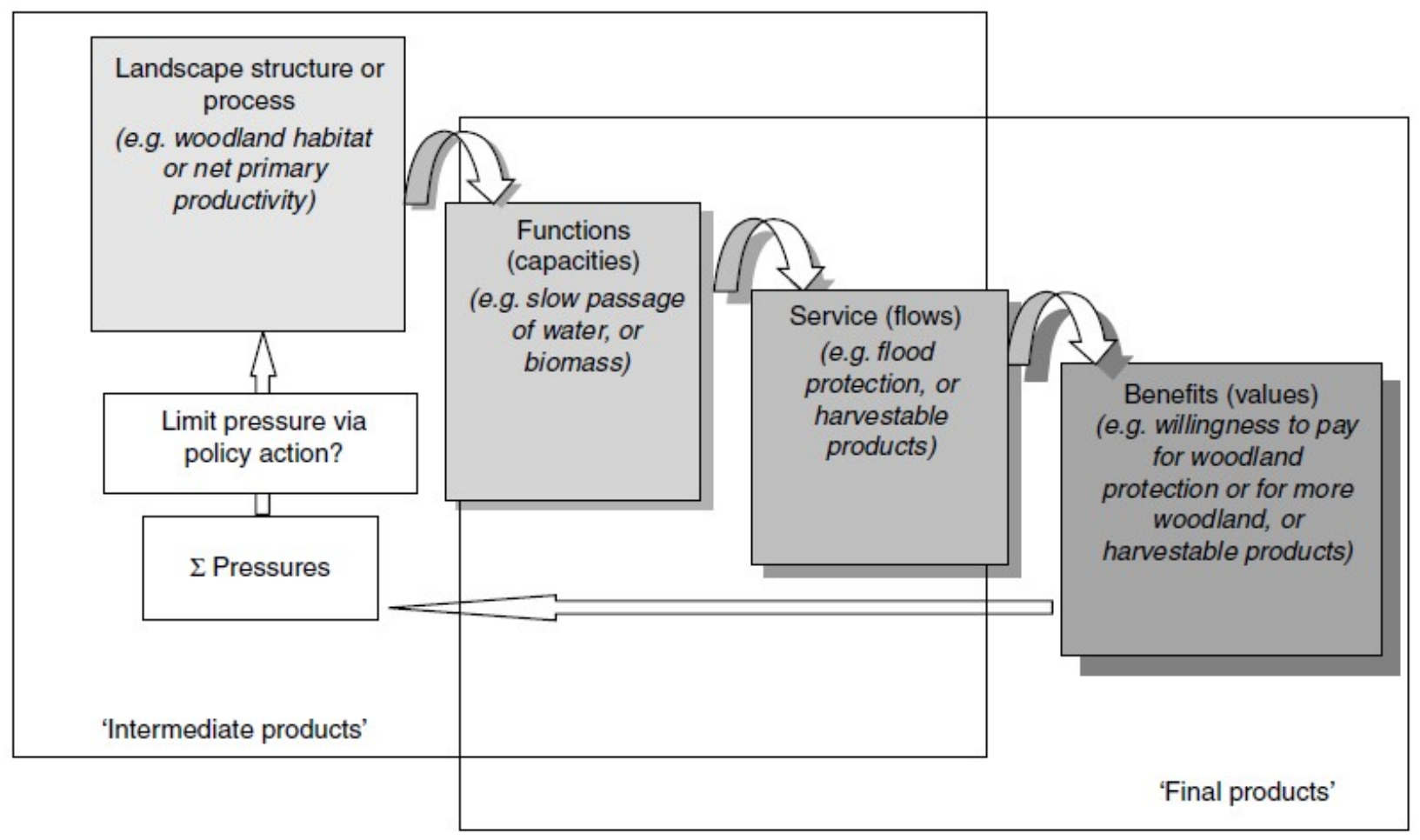

Figure 1: Ecosystem service cascade (Haines-Young \& Potschin 2010) displaying benefits and values on the right hand side of the diagram. 
because "quality indicators for assessing CES are still underdeveloped" (Tenerelli et al. 2016, p. 237), it would be wise to adopt a quality-verifiable method of deriving CES indicators.

The relationship between CES and human wellbeing depends on the relationships between CES supply, demand and flows (see definitions in Burkhard et al. 2014). The assessment of CES supply (left hand side of Fig. 1) and demand (right hand side of Fig. 1) are acknowledge in ES research (Burkhard et al. 2014). However, spatial delineation of supply and demand for intangible CES is a challenging task. The challenge is manifest whenever researchers are unable to formulate indicators for certain CES (Plieninger et al. 2013).

\subsection{Case study Nairobi, Kenya}

Nairobi is the capital city of Kenya with an estimated population of 4-5 million people (Thieme 2015). Ngong forest (www.ngongforest.org, 24.02.2017), Karura forest (www.friendsofkarura.org/thekarura-forest-researve, 24.02.2017) and the Nairobi National park (www.kws.go.ke/parks/nairobinational-park, 24.02.2017) surround Nairobi city. The city is thus described as a haven for serenity and beauty by Barbara Wood ${ }^{1}$. As new opportunities for employment and business emerge in the city, a large human population from rural area to Nairobi city is expected. Consequently, there is a mounting stiff competition for space between built-up areas and green spaces. The competition is in favour of built-up areas, mainly because of its direct economic gains (Mundia \& Aniya 2005). Land use change in Nairobi occur in both private and public land ${ }^{2}$. Public

1 Barbara Wood is an international bestselling female novelist in the United States of America. Her books are thrilling to readers and have been highly rated. The Green City in the Sun depicts the beauty of Nairobi as seen by the British during the colonial period.

2 Public land is "land lawfully held, used or occupied by any State organ, except any such land that is occupied by the State organ as lessee under a private lease ... land in respect of which no individual or community ownership can be established by any legal process" (Constitution of Kenya, Article 62 (1) b \& d). Private land is "registered land held by any person under any freehold tenure; land held by any person under leasehold tenu- land such as public parks, forests and arboretums, have experienced dramatic modifications in the past, especially as a result of public land grabbing. For example, the Ndung'u land report ${ }^{3}$ state that the "issuance of selective title deeds to Karura and Ngong Forests for example deliberately excluded a total area of 1125.5 ha from titled areas. The areas left out were then illegally and irregularly allocated to private developers". Diminishing public spaces in urban areas may result to an overall reduction of human wellbeing and quality of life (Thompson 2002, Chiesura 2004). For example, it has been confirmed that the presence of forests, public green parks and public recreation sites in urban areas has a positive effect in reducing stress, facilitating physical and mental healing, strengthening social cohesion and community identity (Chiesura 2004, Francis et al. 2012). The stated benefits emanate from CES (MA 2005). The peri-urban areas, as the new frontiers of urbanization in the $21^{\text {st }}$ Century, set a central stage for investigating relationships between CES and human wellbeing.

\subsection{Objectives of the study}

The aim of this paper is thus to elaborate on CES indicators and to demonstrate the linkages between CES and human wellbeing in a practical case study in Kenya. In line with this aim, we want to address the following specific questions;

\section{1) How can CES indicators be identified?}

2) How can CES indicators be qualified using social, cultural and psychological sciences?

3) How are CES and human wellbeing interconnected?

4) What do the interconnections communicate to the local people, decision-makers and ES research community?

re" (Constitution of Kenya, Article 64 (a) \& (b)), www.kenyalaw. org (24.02.2017).

3 The Ndung'u land report is a detailed account of public land grabbing since Kenya's independence in 1963. http:// kippra.or.ke/index.php?option=com_docman\&task=doc_ view\&gid $=254 \&$ Itemid $=$, 24.02.2017 


\section{Reviewing indicator frameworks}

\subsection{Cultural ecosystem services indicators}

Although the applications of CES indicators in ES research are limited (Feld et al. 2009), there is a wide spectrum of frameworks that attempt to derive, define and apply CES and their indicators in environmental planning, management and policy-making. For example, Willemen et al. (2008) delineated cultural heritage and tourism as CES indicators in the landscape by use of literature and socio-economic data. Similarly, the World Conservation Monitoring Centre describe the process of developing and classifying ES indicators (UNEP-WCMC 2009). UNEP-WCMC (2009) report that the exercise of deriving ES indicators has five steps; ecosystem condition, ecosystem functions and process, ecosystem services, benefits to human wellbeing, and holistic impacts to human wellbeingan exercise that becomes difficult as one moves from the biophysical state of the ecosystem to the socioeconomic state of human beings. Chan et al. (2012, p. 15) provide a framework of deriving CES benefits and values, and propose that non-market CES indicators and their benefits and values, "must be discovered on site". Tratalos et al. (2016) propose a CES indicator framework based on either the supply or demand of a service. The supply-side indicator framework acquired data and information from literature about (semi-) natural environmental conditions that are associated with cultural benefits. On the other hand, the demand-side indicator framework assesses the actual flow of cultural benefits based on outcomes of community inquiries and surveys. The process of refining guidelines for developing a classification of ecosystem service indicators culminated with complete frameworks in form of tables and figures for both the scientific and policy applications (BIP 2011; Brown et al. 2014).

The underlying similarities in all of the proposed frameworks are; the need for an inclusive and participatory process for all stakeholders, identification of conservation objectives, identification of relevant, practical and cost-effective indicators to address stated objectives, and to be transparent in communicating results for purposes of supporting policy and decision-making.

A literature overview of CES and their indicators is presented in Tab. 1. Similarly, an overview of elaborated guidelines of the qualities and criteria for selecting environmental (ecosystem services) indicators is discussed in the literature (Niemeijer \& De Groot 2008; Potschin et al. 2016).

\subsection{Human wellbeing indicators}

The study of 'wellbeing' was founded on the Aristotelian eudaimonia concept of 'happiness' (Ryff 1989; Diener \& Suh 1997) as the optimal gain that could emanate from the human search for a good life. In the 1950s, psychologists understood 'happiness' as a construct of the mind (Neugarten et al. 1961; Seligman 2011), and that high psychological wellbeing resulted in high happiness. It is argued that it is incorrect to equate or subjugate 'wellbeing' to 'happiness'. Consequently, Shin \& Johnson (1978) defined wellbeing in terms of 'quality of life'. In order to rate quality of life for an individual, the commonly used reference point is the society in which standards are set (Neugarten et al. 1961) as compared to individually set standards, that is, measuring the variance between an individual's score and a collective societal score. This recognizes the dynamic nature of the human society where standards of measuring quality of life change in respect to societal changes.

The dilemma of how best to define 'wellbeing' prompted authors to re-visit the term 'equilibrium state of wellbeing qualities' (Headey \& Wearing 1992; Dodge et al. 2012), which had undoubtedly evoked widespread criticism (Herzlich 1973). The criticism argues in line with the ecological view that 'equilibrium' is a hypothetical and desirable state (Stone et al. 1996), and that referring to an equilibrate state of wellbeing and the societaldriven dynamics of wellbeing in the same breath is a misnomer. For several decades since the 1940s, the term 'wellbeing' has thus been extensively discussed in health disciplines such as the clinical psychology, psychiatry, social psychology (Dodge et al. 2012) and in utilitarian economics (Alkire 2002). It is thus unsurprising for the World Health Organisation 
(WHO) to have made concerted efforts to define 'quality of life' (synonymous with wellbeing) (WHO 1997). What is striking in the WHO's definition is the inclusion of the term 'environmental wellbeing', which was conspicuously missing in earlier descriptions. There is evidence that the evolutionary research on the terms 'quality of life' and 'wellbeing' shaped the crafting of the Millennium Development Goals (MDGs) (www.un.org/millenniumgoals/, 24.02.2017) and the resolutions of the World Summit on Sustainable Development (WSSD) (www. un.org/events/wssd, 24.02.2017). For example, the term 'wellbeing' appears in ten different sections of the WSSD report (United Nations report on the World Summit on Sustainable Development, Report No. A/CONF.199/20) and that the indices for assessing 'quality of life' have been extensively used to measure the transformation achieved in different countries in line with the MDGs targets ${ }^{4}$ . The theoretical representation of how ecosystem services are intertwined with human wellbeing was demonstrated by the MA (2005), which captures and advances the earlier proposed concepts of 'physical resources' (Herzlich 1973) and 'environmental mastery' (Ryff 1989).

Physical wellbeing is part of the seven human wellbeing domains presented in the advanced research by the Puget Sound Institute (Biedenweg et al. 2014). Physical wellbeing of people depends on the availability, quantity and quality of natural resources. In this context, the Sustainability Society Foundation states that, "human wellbeing without environmental wellbeing is a dead end, environmental wellbeing without human wellbeing makes no sense, at least not from an anthropocentric point of view" (SSI 2014, p. 14). The recognition that wellbeing depends on both the state of mind (subjective indicators of wellbeing) and conditions outside one-self (objective indicators of wellbeing) (Canaviri 2016), demonstrates the complexity of assessing wellbeing. In addition to subjective wellbeing indicators, whose awareness is still limited to date (Alkire 2002), it is argued that wellbeing- as

4 The MDGs targets were evaluated annually for fifteen years for different countries until the launch of the Sustainable Development Goals (SDGs) in 2015 and also referred elsewhere as 'Beyond MDGs' a multidimensional concept- requires composite indicators, which have characteristics of objectivity (Canaviri 2016).

2.2.1 Composite, objective, social and subjective indicators of wellbeing

Composite indicators "should ideally measure multidimensional concepts which may not be captured by a single indicator, such as competitiveness, industrialization, sustainability, wellbeing, development and progress, single market integration or knowledge-based society" (Canaviri 2016, p. 37). A composite index is thus formulated by aggregating and weighting a group of individual indicators (Canaviri 2016). This process eliminates redundancies that originate from double counting and error in measurement of individual indicators, provide opportunity to learn and act together, eliminates subjective perceptions, as well as ensuring wellbeing comparability across countries and regions (Diener \& Suh 1997, Canaviri 2016). At this point, it should be noted that the aim of composite and social indicators of wellbeing is to achieve ends with high objectivity. Objectivity in wellbeing science is about reconciling the effect of aggregation and weighting of individual indicators on one hand, while on the other hand ensuring adequate coverage of the wide spectrum of wellbeing parameters. For that reason, the term 'objective' refers to both composite and social indicators, and that the terms 'composite' and 'social' are interchangeably used when referring to wellbeing indicators in this paper. The European Joint Research Council lists thirty composite indicators of wellbeing alongside details about the developer, attributes measured and their descriptions, number of indicators used, and the number of entities assessed (Saisana \& Philippas 2012). More composite indicators are presented in the literature (Malik 2013; Canaviri 2016; OECD ${ }^{5}$ 2015; Alkire 2011; Neugarten et al. 1961; Bérenger \& Verdier-Chouchane 2007; Seligman 2002a; Dodge et al. 2012; WB 2016).

\footnotetext{
5 The Organisation for Economic Co-operation and Development (OECD) and its Better Life Index for measuring wellbeing. http://www.oecd.org/statistics/How-s-life-2015-60-secondeguide.pdf (24.02.2017)
} 
Subjective indicators of wellbeing investigate the level of satisfaction, happiness and fulfilment of individuals. Diener and Suh (1997) discuss the merits of subjective wellbeing, whereby the researcher and the interviewees could timely intervene to correct indicator inadequacies, be able to document individual experiences and to easily compare one indicator across different societies. Although comparability in subjective wellbeing indicators may be contested by proponents of objective indicators, Diener and Suh (1997) contextualize situations where 'personal fulfilment', for example, has one value of measurement in comparison to several domains (health, education, and living standards) measured under the Human Development Index (HDI) as an objective indicator (Canaviri 2016).

Diener and Suh (1997) outline the weaknesses of social and subjective indicators. The most striking weaknesses for social indicators stem from the fact that: although child mortality for example, is an acceptable measure of social wellbeing in the world, the same rate of child mortality in two countries may be interpreted differently based on the level of development and reference point; there is difficulty in differentiating between goals and means of an indicator-for example, a high number of public health officers may be a result of poor health conditions in a given settlement or a healthy population may be a result of high number of public health officers; after aggregation and weighting processes, composite indicators result in oversimplifications and hence are losing the information of individual indicators. Similarly, subjective wellbeing indicators are vulnerable to popular historical occurrences, are susceptible to personal temperament and social cues, and individuals from one society may respond fully to a wellbeing indicator question whereas a section of individuals from another society may abstain from responding to the same wellbeing indicator question. After analysing both subjective and social indicators of wellbeing, Diener and Suh (1997, p. 200) state that, "as researchers realized the imperfect relation between objective conditions and psychological wellbeing, many accepted the importance of directly assessing the subjective, experiential elements of well-being". Nevertheless, Diener and Suh (1997, p. 207) conclude that "social indicators and subjective wellbeing measures are complementary". Although the assertion is worth noting, investigating the complementarity between social and subjective wellbeing indicators is outside the scope of this paper. After analysing the literature arguments and the interests of a case study methodology, the paper focuses its attention on the subjective wellbeing and its connection to CES as presented in section 2.1.

\section{Materials and Methods}

\subsection{Description of case study area}

The case study was carried out in a peri-urban area adjacent to the city of Nairobi, Kenya. The study area is hived from parts of Nairobi and Kiambu Counties (www.iebc.or.ke, 24.02.2017) and its boundaries have been delineated by research interests rather than by administrative districts. The area borders the Machakos County in the East and the Murang'a County in the North, and comprises of Constituencies and County Assembly Wards (www.iebc.or.ke, 24.02.2017) with similar demographic and physical infrastructural patterns. It has an estimated area of $793.15 \mathrm{~km}^{2}$ and an approximated population of 1.6 million $^{6}$. The western and southern parts are characterised by a cool highland climate and fertile soils conducive for farming (Makachia 2011) with high altitudes of up to 1,670 m a.s.I (K'Akumu and Olima 2007). The south-western part encompasses the Karura forest (Fig. 2), which is a public forest protected according to the Forest Conservation and Management(www.environment.go.ke, 24.02.2017) ACT 2014/15 in Kenya. The forest policy underpins the joint role of community forest associations (CFA) (www.friendsofkarura.org, 24.02.2017) and the Kenya forest service (KFS) (www.kenyaforestservice. org, 24.02.2017) in the co-management of public forests. The joint management has succeeded in ensuring sustainable consumptive and nonconsumptive benefits to people around the forest

6 Population estimates are based on the Kenya Population and Housing Census 2009 report by the Kenya National Bureau of Statistics (www.knbs.or.ke, 24.02.2017). 
and the entire country. Cultural ecosystem services have been of high importance for urban and periurban population (Dobbs et al. 2011). For example, the cultural and ecotourism activities at the Karura forest have been attracting an estimated number of 200,000 visitors annually (www.friendsofkarura. org).

\subsection{Research design}

The study is based on a survey method. To prepare and coordinate the survey exercise, the study area was divided into six interview centres (see Fig. 2). Each centre was identified by the name of the most popular town/ name of a government administrative area in its neighbourhood. Each centre enclosed at least one Constituency and several units referred to as Wards ${ }^{7}$. Each centre has an estimated average

$7 \mathrm{~A}$ Ward is the smallest electoral unit in Kenya, and it forms the basis of the devolved County governments. www.iebc.or.ke (24.02.2017) of 60000-100000 potential interviewees ${ }^{8}$, who also met the legal adult age $e^{9}$ criteria. Since the legal adult population is exclusive, it differs significantly, on the lower side, with the population number provided in sub-section 3.1. Therefore, the target interviewees

8 The population estimation per centre is based on the 'population quota' approach provided for by Article 89 (12) of the Constitution of Kenya. The 'population quota' per Constituency (several Wards make a Constituency) assumes an equal distribution of people by dividing the total national population (at any given time) by the capped 290 constituencies (Constitution of Kenya 2010). However, the number of potential interviewees per centre is determined by the discriminative approach targeting only individuals aged 18 years old and above. A sampling frame from the Independent Electoral and Boundaries Commission (IEBC) was used

9 At the age of 18 years, a Kenyan citizen can apply to be issued with the National Identity Card, which is the legal official document for identifying and transacting with all government offices and the legally registered institutions and entities in the republic of Kenya (www.immigration.go.ke/AboutUs.html, 24.02.2017)

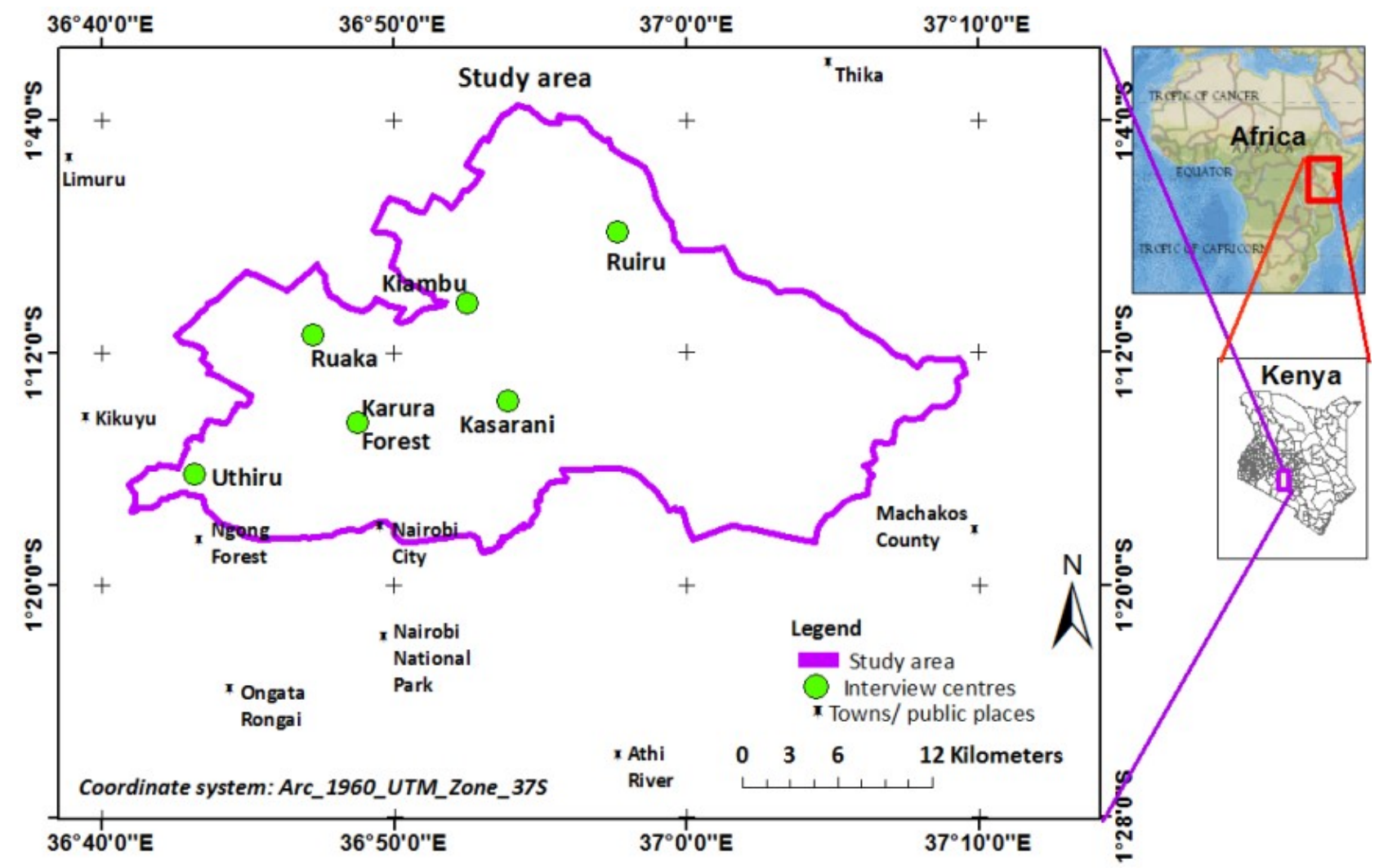

Figure 2: Geographical location of the case study within Nairobi-Kiambu peri-urban area. 
were both male and female at the age of eighteen years and above. Interviewees from each of the six interview centres were selected using random sampling for the survey. The interviews were conducted during the day time and the respondents were selected without special attention to age, gender or occupation (e.g. students, farmers and business people). Primary data of CES was collected through questionnaires, interview schedules, matrix tables and field observation sheets. The pen-andpaper method was used to record feedbacks from the interviewees. In cases where a respondent had limited time for the interview, the Olympus Digital Voice recorder DS-75 was used. Secondary data was sourced from peer reviewed publications, reports, statistics periodicals and land use maps. The exercise for collecting both the primary and secondary data was conducted in two phases. The first phase was conducted between July 2014 and January 2015 (113 interviews conducted) and the second phase from November 2015 to February 2016 (24 interviews with actual visitors to sites of CES). Data analysis was conducted using the Statistical packages for Social Sciences (SPSS) and MS Excel. Both empirical and qualitative results were organized and presented in form of tables, figures and conceptual frameworks.

\subsection{Identifying and ranking potential CES indicators}

In order to familiarize with the geographical and demographic patterns of the study area, field visits and observations (Petty et al. 2012) were carried out for ten days between $21^{\text {st }}-31^{\text {st }}$ July 2014 . Using literature and the study area characteristics, as proposed in the method by Mascarenhas et al. (2016), we identified thirteen sub-categories of CES (Tab. 1). In order to validate the listed CES, seventeen respondents (seven academic experts and ten local people) were selected for a piloting exercise. The piloting was aimed at testing whether the CES subcategories were mutually exclusive for independent investigation and that aggregating or disaggregating any of them would mount to substantive loses of crucial information (Potschin et al. 2016). Each session began by an introduction on 'ecosystem services' and their different categories as stipulated by Kandziora et al. (2013). The interviewer then elaborated on CES. A copy of the thirteen CES sub- categories (Tab. 1) was then presented again to the respondents. The respondents evaluated the CES sub-categories regarding their suitability for the study. After the suitability evaluation, the thirteen sub-categories were reduced to ten sub-categories (see sub-section 4.1). Since the study targeted five CES sub-categories for in-depth investigation, the ten validated CES sub-categories were further subjected to a ranking exercise. The 'bidding game' ranking exercise was used, where each individual ranked each of the validated CES sub-categories by using a scale of 1 to 10 (see Supplementary Tab. 4). The ranks 1 and 10 meant the least important and the most important CES respectively, following the indicator ranking guidelines by Biedenweg et al. (2014). The 'bidding game' ${ }^{10}$ question stated, "Which score of importance between 1 and 10 would you assign to cultural ceremonies?" This question was repeated for each CES sub-categories. After having received all responses, a geometric mean ${ }^{11}$ value was calculated for each of the ten CES sub-categories in SPSS. The ranking results (geometric mean for the ten CES sub-categories) were used to select five CES sub-categories for the in-depth investigation in the survey. Thereafter, we randomly identified and recorded any natural, human and semi-natural entities, features, objects and landscapes that could indicate each of the five CES sub-categories. Three potential indicators for each CES were identified and this resulted into fifteen potential indicators. In order to validate the indicators, the methodological steps in section 3.2 were applied. Our 'bidding game' question stated, "Which score of importance between 1 and 10 would you assign to cemeteries as an indicator of the cultural ceremonies?" For each CES, we used SPSS to calculate the geometric mean

10 Bidding game is not hereby used in its pure economic interpretations of value (Frew et al. 2004) but interpreting the concept on a calibrated ruler drawn on a paper with a minimum value on the left hand side and maximum value on the right hand side for purposes of ranking only. Since each CES have some level of importance, the minimum value is one (not zero) and the maximum value is equal to the number of CES (in this case, ten).

11 Geometric mean was preferred for purposes of treating the pilot respondents as different as possible and hence minimizing the impact of a score from one respondent to the scores of other respondents and vice versa. 
for each of the three indicators from the seventeen respondents and picked two indicators with the highest geometric mean score of importance. In the end, each CES was represented by two indicators and a total of ten indicators for the five CES subcategories. Further, principal component analysis $(P C A)^{12}$ was performed using IBM SPSS Statistics 23, in order to generate a correlation matrix and explain the variance among the CES indicators. The KaiserMeyer-Olkin (KMO) measure of sampling adequacy was used to determine the importance of the PCA analysis. The PCA and KMO results are presented in section 4.2. Details on the correlation matrix of the CES indicators are provided in the supplementary Tab. 5.

\subsection{Qualifying CES indicators}

In order to qualify each of the ten selected CES indicators, a link to human wellbeing was to be established. Nine constituents of human wellbeing (HWB) that are describing the people and the study area were selected based on the social, cultural and political information available. The HWB constituents include personal happiness, physical health, indigenous/ contemporary knowledge, peace and harmony, sense of belonging, symbolic instrumental value, psychological nourishment, social concretization, and emotional support (defined in Supplementary Tab. 3) (modified after MA 2005). Using the procedure set in sub-section 3.3, five constituents of HWB were adopted for the research. Both the CES and human wellbeing were further presented in a matrix table (CES indicators on the $x$-axis and subjective HWB indicators on the $y$-axis, Supplementary Tab. 1). The advantages of the subjective HWB indicators are elaborated by Diener and Suh (1997). In this study, the subjective HWB indicators were adopted because:

12 "Principal components analysis (PCA) is a powerful statistical tool that can help researchers analyze datasets with many highly related predictors. PCA is a data reduction techniquethat is, it reduces a larger set of predictor variables to a smaller set with minimal loss of information. PCA may be applied before running regression analyses or for exploratory urposes to help researchers understand relationships among their variables or discover patterns in their data" (Sainani 2014, P. 275)
- Subjective HWB indicators can more accurately reflect the degree of CES-Human wellbeing interaction at a local scale than objective wellbeing indicators.

- It is easy to capture personal judgements and experiences about CES-wellbeing interactions.

- Subjective HWB indicators can be easily modified to capture the most relevant details.

- Results from Subjective HWB indicators give the most realistic values that can give realistic comparisons with other areas.

During the interviews, the interviewees were asked to qualify each CES indicator in terms of its contribution to each of the five constituents of HWB using a scale of 0 to 5 ; (where $0=$ no relevant importance, $1=$ very low relevant importance, 2 = low relevant importance, $3=$ medium relevant importance, $4=$ high relevant importance, $5=$ =very high importance) (translated in Swahili language for the local people, see Supplementary Tab. 1). The data collected using all questionnaires $(n=113)$ was entered into SPSS and the mean values were calculated for each indicator. The mean values reflect the potential importance of the particular CES indicator to HWB. The mean values were visually displayed via spider diagrams, which were generated using MS Excel. Other statistical analyses such as descriptive statistics and principal component analysis were conducted in SPSS, and figures were used to explain the differences among- and correlations between the individual CES indicators.

\subsection{Revealing interconnectivities between CES and human wellbeing}

The interconnectivity between CES and HWB was adopted by the 'ecosystem services cascade' (Haines-Young \& Potschin 2010) and the cascade model was merged with the DPSIR model (Nassl \& Löffler 2015). The version of the 'ecosystem service cascade' by Haines-Young \& Potschin (2010) was preferred because it is simple by design, and adequately provides visualized details of the stepwise connection from the landscape structures (especially for the highly modified urban and peri-urban areas) and processes on the one hand, through function 
and ecosystem services in the middle, and benefits and human wellbeing on the other hand. The DPSIR framework was adopted because of its ability to convey information about causes and effects within socio-ecological systems and supporting policy and decision- making in response to the undesirable causes and effects. Using interviews' responses from real visitors of CES sites $(n=24)$ at Karura forest, six categories of information were compiled and analysed. Six cascading pillars running from left to right were identified and presented in the following order; (i) the ecological structures and processes, (ii) potential suitable landscape types, (iii) cultural ecosystem services flow, (iv) society state of benefits and wellbeing constituents, (v) group values, and (vi) environmental action and policy change. The data for the first and second pillar emanated from observations and field interviews about the natural landscape and cultural features. The third pillar comprises of respondents' interview data about hobbies and cultural activities. The fourth pillar presents the five selected constituents of wellbeing that are likely to be boosted by the hobbies and cultural activities. The fifth pillar shows how individuals' wellbeing practically transforms into social values with an element of organisation. In the sixth pillar, in-depth inquiry about the intentions of people organizing themselves into groups, and the feedbacks were summarized and recorded in the context of influencing environmental and

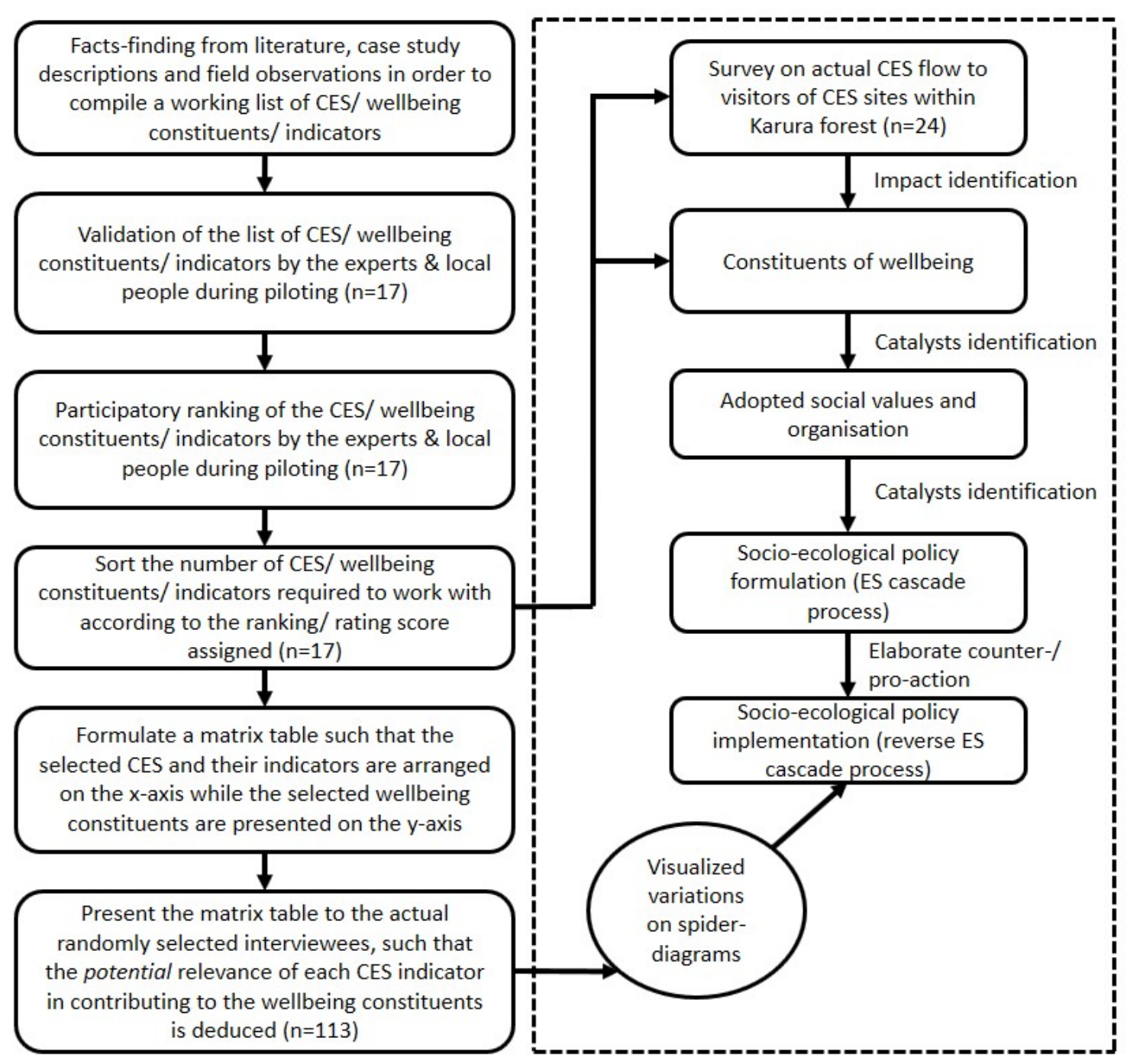

Figure 3: A summary of the methodology applied in the study. The dotted lines enclose the components that are integrated into the DPSIR model. $n=17$ represents respondents contacted for questionnaire pre-testing, $n=24$ and $n=113$ indicate the number of respondents in the respective survey exercises for the two fieldwork phases. 
biodiversity management action. The six pillars of data were analysed in SPSS and Excel and their interconnectivity was demonstrated within the revised DPSIR model framework according to NassI \& Löffler (2015). A stepwise representation of the methods and methodology for the study is portrayed in Fig. 3.

\section{Results}

\subsection{Validating and ranking cultural ecosystem services}

The validation exercise reduced the number of CES from thirteen (Tab. 1) to ten sub-categories as follows; (i) recreation and tourism, (ii) landscape aesthetic and amenity, (iii) knowledge, education and science, (iv) religious, spiritual and sacred experience, (v) cultural heritage and cultural diversity, (vi) natural heritage, natural diversity and existence, (vii) inspiration and art, (viii) social relations, (ix) sense of place, and ( $x$ ) ceremonial (place- based). Although entertainment, symbolic and bequest cultural services were perceived to be important, most respondents argued that entertainment was well covered under recreation and tourism and ceremonial sub-categories of CES.
Likewise, symbolic was represented under cultural heritage and cultural diversity and inspiration and art sub-categories of CES. Most respondents had difficulties to understand and identify themselves with the bequest CES and hence they could not confirm or rule out its importance to the local people and its mutual exclusivity from the other sub-categories of CES. The three CES sub-categories were thus excluded from the ranking exercise. The ranking exercise resulted into the five sub-categories of CES (landscape aesthetics and (amenity), cultural heritage and (diversity) identity, cultural ceremonies, recreation and tourism, and religious retreats and pilgrimages), which had the geometric mean score of 7.4, 7.9, 7.6, 8.1 and 8.7 respectively. It is noted that during the ranking exercise, slight modifications took place where the term 'amenity' was removed, whereas 'diversity' was preferably replaced by terms like 'identity'. The term 'cultural' was co-opted to the term 'ceremonies', and 'retreats' and 'pilgrimages' were co-opted to 'religious'.

The indicator selection results for the five CES subcategories are presented in Tab. 2. The two most suitable indicators (by ranking) for each CES subcategory are written in italics under column two. For example, the most suitable and practical indicators for cultural ceremonies in the study area are 'wedding gardens' and 'traditional music theatres', which have a geometric mean score of 6.02 and 4.88 respectively.

Table 1: A literature overview for the definitions of cultural ecosystem services indicators.

Cultural Definitions
ecosystem
services

Recreation/ MA 2005; Willemen et al. 2008; Gee \& Burkhard Number of visitors or facilities ( $n$ /ha, n/facility*a), nature and (eco) tourism/ 2010; De Groot et al. 2010; Chan et al. 2012; leisure preferences, turnover from tourism (D/ha*a) (Kandziora Kandziora et al. 2013; Plieninger et al. 2013 et al. 2013); number/area of landscape \& wildlife features with stated recreational value (De Groot et al. 2010).

Landscape Costanza et al. 1997; MA 2005; Gee \& Burkhard aesthetic/ 2010; Chan et al. 2012; Daniel et al. 2012; amenity Kandziora et al. 2013; De Groot et al. 2010; CICES Preferences from questionnaires, scenic beauty estimation via landscape metrics, travel cost estimation, willingness to pay (Kandziora et al. 2013); Number/area of landscape features with stated appreciation (De Groot et al. 2010); Qualitative by perceptual surveys, quantitative averaging of choices and ratings landscapes (Daniel et al. 2012).

Knowledge/ Costanza et al. 1997; MA 2005; De Groot et al. education/ 2010; Chan et al. 2012; Kandziora et al. 2013; Features with special educational and scientific value/interest (De Groot et al. 2010); number of environmental educationalscience/ Plieninger et al. 2013; CICES V4.3, 2013 related facilities and/ or events and number of their users (n/ha*a) (Kandziora et al. 2013). 
Table 1: Cont.

Religious/ Costanza et al. 1997; MA 2005; De Groot et al. Presence of landscape features or species with spiritual value spiritual experience/ 2010; Chan et al. 2012; Kandziora et al. 2013; sacred Plieninger et al. 2013; CICES V4.3, 2013 (De Groot et al. 2010); number of spiritual facilities and number of their visitors for performance of rituals and maintain the relationship with ancestors ( $\mathrm{h} / \mathrm{ha}, \mathrm{n} /$ facility*a) (Kandziora et al. 2013).

Cultural heritage/ cultural diversity

MA 2005; Willemen et al. 2008; Kandziora et al. 2013; De Groot et al. 2010; Daniel et al. 2012; Chan et al. 2012; Plieninger et al. 2013; CICES V4.3, 2013

Questionnaires on local people's personal preferences, number of employees in traditional land use forms ( $\mathrm{n} / \mathrm{ha}$ ) (Kandziora et al. 2013); number/area of culturally important landscape features or species (De Groot et al. 2010); visible material representations of cultural activities on the landscape, landscapes that are linked to intangible heritage (myths, legends, and religious practices) Daniel et al. 2012.

Natural heritage/ natural diversity /existence Inspiration/ artistic

Social relations

Sense of place

Ceremonial Chan et al. 2012
(place-based)

Entertainment CICES V4.3, 2013

Bequest Gee \& Burkhard 2010; CICES V4.3, 2013

Symbolic CICES V4.3, $2013^{2}$ 2013
Number of endangered, protected and/or rare species or habitats (n/ha) (Kandziora et al. 2013); individual species that are linked to intangible heritage (Daniel et al. 2012); 'enjoyment provided by wild species, wilderness, ecosystems, land/seascapes' (CICES V4.3, 2013).

Costanza et al. 1997; Farber et al. 2003; MA 2005; Number/area of landscape features or species with inspirational Gee \& Burkhard 2010; De Groot et al. 2010; Chan et al. 2012; Plieninger et al. 2013; Kandziora et al.

value (De Groot et al. 2010); number of paintings/illustrations, songs, products portraying the resp. landscape/ecosystem (n/landscape type) (Kandziora et al. 2013).

${ }^{1 * * N u m b e r}$ of "sites serving as meeting points with friends" (Plieninger et al. 2013).

**Number of -and quality of available visual and audio materials that display "sites that foster a sense of authentic human attachment" (Plieninger et al. 2013).

Practices performed on specified occasions where certain food, clothing, songs and spatial location for events carry a deep meaning of cultural identity and a time, rites of transition.

**Number of "Ex-situ viewing/experience of natural world through different media" (CICES V4.3, 2013).

Level of "willingness to preserve plants, animals, ecosystems, land-/seascapes for the experience and use of future generations; moral/ethical perspective or belief" (CICES V4.3, 2013).

**Number of "emblematic plants and animals e.g. national symbols such as American eagle, British rose, Welsh daffodil" (CICES V4.3, 2013).

**13, CICES V4.3, 2013 (http://biodiversity.europa.eu/maes/common-international-classification-of-ecosystem-services-cicesclassification-version-4.3, 24.02.2017)

$13^{* *}$ Asterisks refer to an indicator whose measurement dimension was missing from the primary article and hence are hereby added by the authors of this article. For example, the italic terms number of-, level of-. 
Table 2: Five selected cultural ecosystem services and ranking of respective indicators $(n=17)$

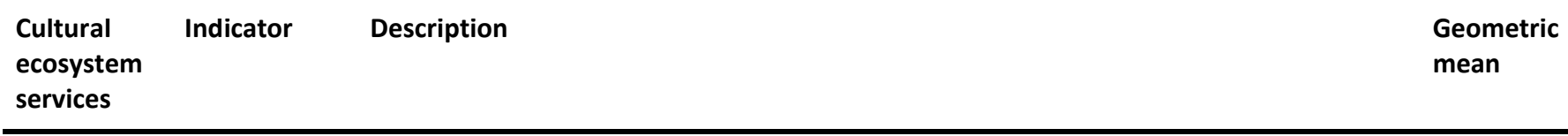

\begin{tabular}{lll}
\hline $\begin{array}{l}\text { Landscape } \\
\text { aesthetics }\end{array}$ & $\begin{array}{l}\text { Hills and } \\
\text { valleys }{ }^{14}\end{array}$ & $\begin{array}{l}\text { Hills are elevated earth surfaces above all other natural features in a given geographical } \\
\text { area. A valley is a conspicuous depression feature that is visible below the normal } \\
\text { geographical terrain of a locality. }\end{array}$ \\
& $\begin{array}{l}\text { Rivers and } \\
\text { streams }\end{array}$ & Natural or semi-natural channels of flowing freshwater \\
& Forests & $\begin{array}{l}\text { A land cover dominated by trees of minimum height of } 5 \text { metres and minimum area of } \\
0.5 \text { hectares (FAO } 2016)\end{array}$
\end{tabular}
Cultural Museums $\quad$ Museums are places where collected objects are preserved and that the objects depict heritage the past and present cultural and historical experiences (Brida et al. 2013;
and Weidenhammer \& Gross 2013)

identity

Artefacts

Monuments Monuments are physical symbols of real history and memory that connect the present to the past (Foxall 2013). They constitute memorials that are used to legitimize or sanctify historical personalities, groups or events in to the present social setup (Alderman \& Dwyer 2009).
Cultural Wedding Wedding gardens are areas part of/ apart of catering and social services on hire to host ceremonies gardens private or public wedding activities. The area also host graduation events, club meetings and parties, as well as birthday celebrations.

Traditional Traditional music theatres are public facilities available for hosting annual music music festivals, purposeful music events, stage and theatre performances, music auditioning theatre and training.

Cemeteries Spatial grounds set aside by the local municipalities for purposes of burying the dead people. Cemeteries are synonymous with urban and peri-urban setting because land is owned via lease agreement with the local authorities. Cemeteries become unpopular as one goes to the interior rural areas where people have free-hold ownership of land.

\section{Recreation Sport- and grounds}

tourism

Social halls

Arboreta and wildlife parks

$\begin{array}{ll}\text { Religious } & \text { Shrines and } \\ \text { retreats } & \text { sacred places } \\ \text { and } & \\ \text { Pilgrimage } & \end{array}$

Sport-grounds are suitable playgrounds, courts and pitches (Harrison et al. 2016) in which sports such as ball-games, athletics, field events (javelin, high and long jumps, short-put, pole vault, discus throw, and triple jump)

Social halls are enclosed/ indoor assembly and recreation buildings (Burgess 1954) with facilities for collective social good, where social and cultural activities are held. The facilities are managed either by the government ministry for social, sports and cultural affairs, or by officially registered religious and social groups. The halls are entitled to youth groups, religious groups, community-based organisations, self-help groups and any other group with a known socioeconomic agenda.

Arboretum is public area dominated by different species of trees. Wildlife parks are areas of recreation and/ or education through wildlife viewing that takes place in an animal sanctuary, an orphanage and game parks.

"'pilgrimage' is a journey based on religious or spiritual inspiration, undertaken by individuals or groups, to a place that is regarded as more sacred or salutary than the environment of everyday life, to seek a transcendental encounter with a specific cult object for the purpose of acquiring spiritual, emotional or physical healing or benefit" (Margry 2008). Shrines are holy and reverenced places with a historical attachment.

Hills and Valleys ${ }^{14}$, FAO (www.fao.org/forestry/fra, 24.02.2017)

14 Indicators in italics were chosen for actual survey. 
Table 2: cont.

\begin{abstract}
Retreat centres

Churches, mosques and temples
\end{abstract}

\subsection{Affinity of constituents of human wellbeing to indicators of cultural ecosystem services}

Fig. 4(ii) shows that personal happiness has the highest affinity for all the CES indicators. The ten CES indicators have mean scores between 2.95 and 4.72. On overall, the selected CES indicators have a minimal contribution to physical health whereby only 'forests', 'sport-grounds' and 'worship places' were found to have at least a medium relevant importance (Fig. 4(iii)). The contribution of CES indicators to the sense of belonging exhibit the smoothest curve from one indicator score to the other and with the lowest variance of 0.19 (Fig. 4(i)). The selected constituents of wellbeing portray the highest affinity for 'worship places', which has a minimum and maximum mean score of 4.20 and 4.72 respectively for all the wellbeing constituents. Forests are perceived to be the second most important CES indicator for the selected constituents of wellbeing, whereas hills and valleys have comparatively the least importance in supporting the selected constituents of human wellbeing. There are noted points of overlaps where different CES indicators have the same score for the same constituent of wellbeing. For example, 'museums', 'music theatres' and 'sport grounds' have a mean score of 3.8 towards personal happiness. Likewise, 'music theatres' 'sport grounds' and 'wedding gardens' have a mean score of 3.6 towards sense of belonging (Fig. 4(iv)). The importance of 'wedding gardens' for emotional support ranks second after 'worship places' with a mean score of 3.3 (Fig. 4 (v)). The minimum and maximum indicator mean values, the convergence and overlap points of all indicators towards all constituents of wellbeing are displayed in Fig. 4(vi).

The Kaiser-Meyer-Olkin (KMO) and Bartlett's test of data suitability for the principal component analysis resulted in a significant sampling adequacy of 0.86 .
All indicators show a positive correlation with each other (Supplementary Tab. 5). 'Monuments' and 'museums' have the strongest positive correlation $(\gamma=77)$, followed by 'arboreta and wildlife parks' and 'monuments', and 'arboreta and wildlife parks' and 'museums' with a correlation of 0.58 and 0.56 respectively. Five indicators (sport grounds, monuments, museums, forests and, arboreta and wildlife parks) have revealed a strong loading of at least 0.50 in reference to the first component. 'Hills and valleys' and 'forests' have the highest loading to the first component with weightings of 0.90 and 0.70 respectively. 'Shrines', 'wedding gardens' and 'worship places' seem to load strongly to the second component with weightings of $0.80,0.60$, and 0.60 respectively.

4.3 Inter-linkages between the cultural ecosystem services and human wellbeing within the socioecological system

Figure 5 displays results of six cascading pillars ${ }^{15}$ from left to right (ecological structures and processes, potential suitable landscape types and human inputs, cultural ecosystem services flow, society state of benefits and wellbeing constituents, group values and social organisation, and environmental action and policy change) and five layers of information from top to bottom (Fig. 5a-e). Fig. 5b shows an extended cascade with two additional pillars namely; the group values (social organisation) and the environmental

15 The six pillars do not represent any form of hierarchy, but show a different form of information or interpretation. Pillars $4 b$-e comprise of information in boxes that are horizontally following each from left to right and the information is sequentially interpreted in that order. Information for Pillar $4 a$ is sequentially interpreted from right to left and pillar $4 b$ aids in that interpretation forthwith. That is, pillar $4 b$ can have either right-left or left-right sequence of information interpretation. 
action and policy change. The single-headed arrows point to the direction of generated effect from the previous step or the direction of the 'cascades'. The double-headed arrows indicate a possibility of forth or backward movement of the process. Within the DPSIR model, ecological drivers (eco-drivers) and anthropogenic drivers (anthro-drivers) are both recognized as sources of pressures towards the state of ecological structures and processes and the state of societal benefits and wellbeing respectively. There are two processes displayed; the DPSIR causal chain of socio-ecological disturbances and the DPSIR causal chain of addressing socio-ecological disturbances.

The terms for the six cascading pillars (Fig. 5b) are defined using ecological theory. Fig. $5 d$ presents the practical descriptive terms of the cascade pillars, which were revealed by the field observations and interviews' results. Fig. 5e refers to composite terminology that is derived from both ecological- and social-based theories for purposes of transparent communication to stakeholders. For this reason, both the ecological structures and processes and the potential suitable landscape types and human inputs are collectively referred to as 'biophysical and cultural environment'. The descriptions of cultural ecosystem services flow are referred to as 'hobbies and cultural activities', whereas the composite term for the society state of benefits and wellbeing constituents is 'wellbeing constituents'. All the descriptions for the group values and social organisation pillar are referenced as 'social organisation' and the environmental action and policy change and its descriptions are referred to as the 'policy process'.
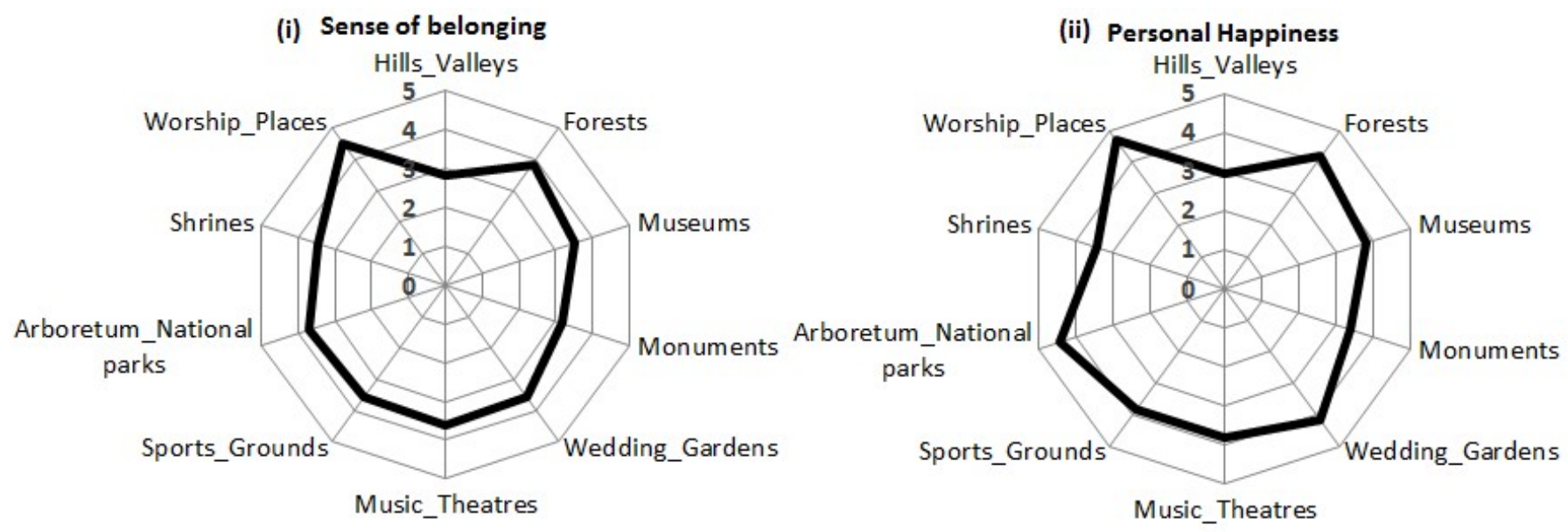

(iii) Physical health Hills_Valleys

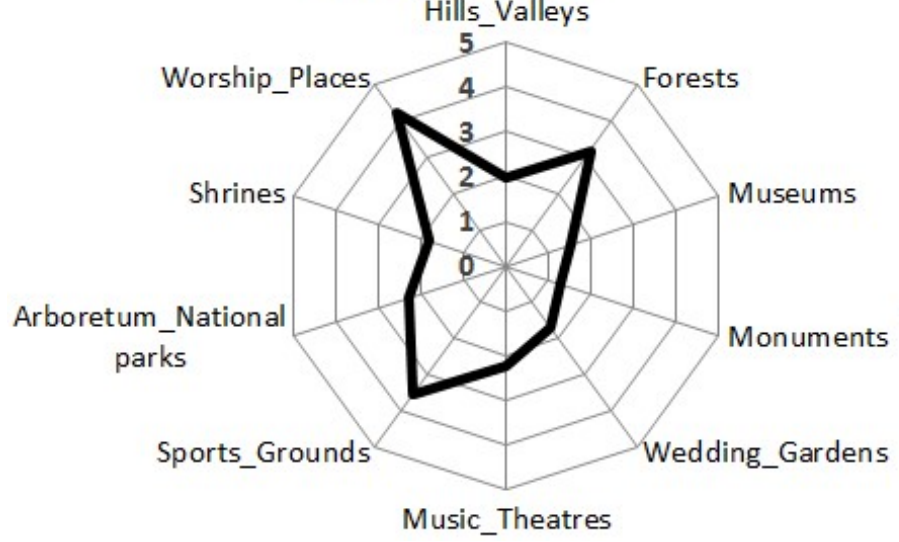

(iv) Source of knowledge

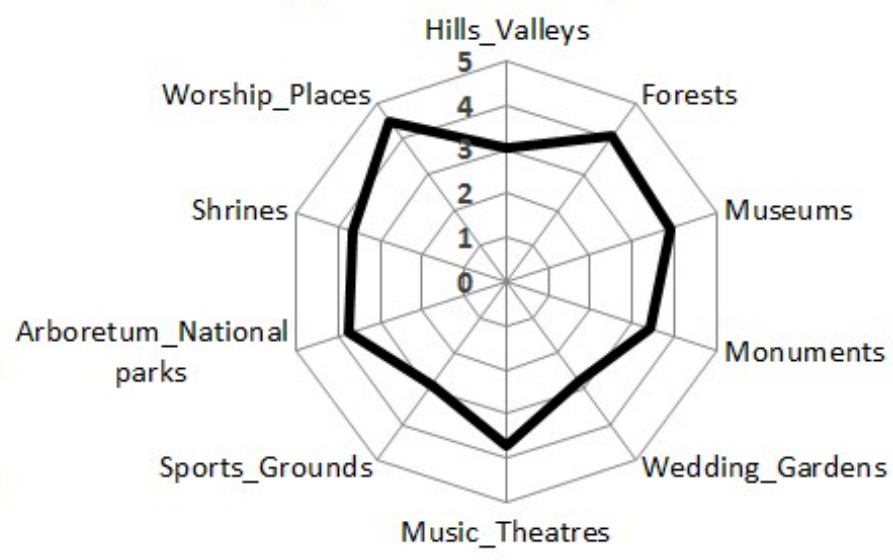

Figure 4: Qualitative importance of selected CES indicators (i-v) in relation to selected constituents of human wellbeing and their comparisons (vi), $n=113$ 


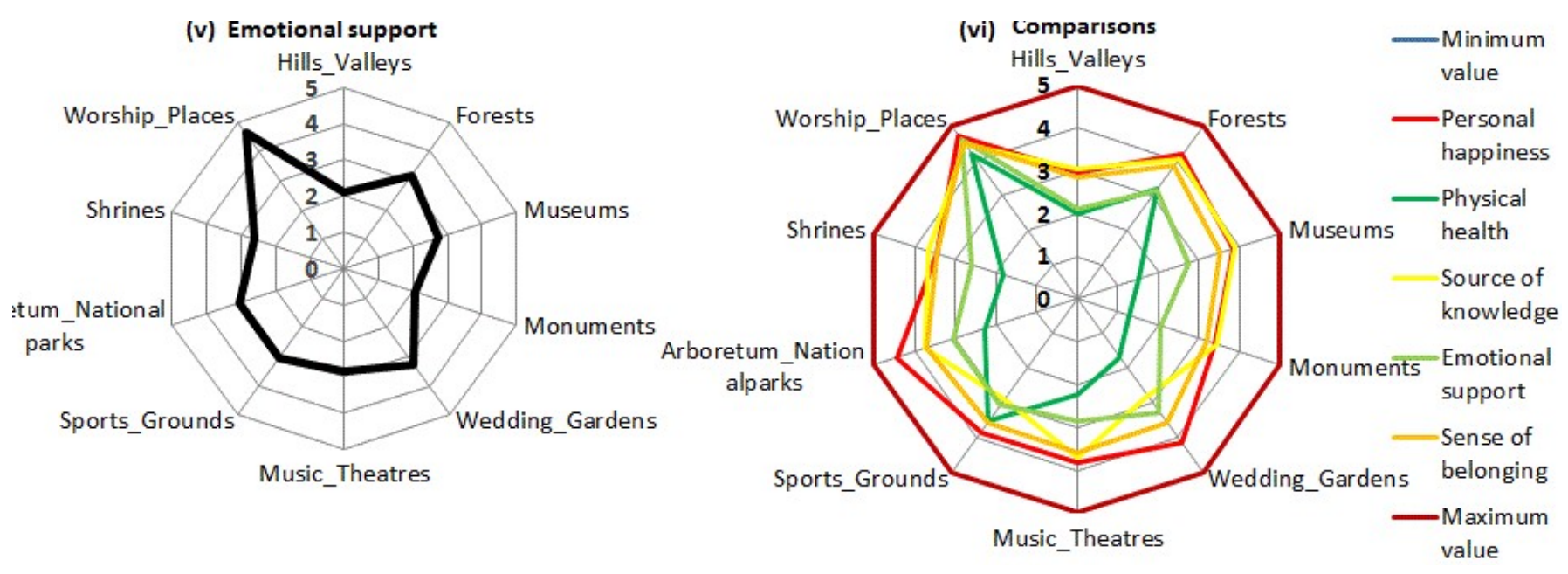

Figure 4 cont.

\subsubsection{The DPSIR causal chain of socio-ecological disturbances}

The left-to-right DPSIR model flow (Fig. 5c) represents the commonly used Driver-PressureState-Impact-Response chain. It starts with a doubleheaded arrow between the eco-drivers and the state of ecological structures and processes at the top-left corner of the framework. Pressures on land cover and landscape maintenance (synonymous with ecological structures and processes) have effects on the state of 'potential suitable landscape types and human input', for example, wetlands, forests, parks, shrines, museums et cetera.

The quality of the CES flow through hobbies such as hiking, jogging, meditation and photography, can be impacted. An impact on CES has a direct impact on the state of societal benefits and wellbeing. Consequently, the collective societal response is launched using social groups, who present their petitions meant to advise on mitigation and adaptation strategies needed for implementation by the environmental management action and policy institutions in order to cope up with the consequences of natural fires, droughts, storms et cetera, that could have significantly altered the flow of CES. When the DPSIR model is based on anthropogenic drivers, the response would target the ecosystem management and policy change such as rational extraction of ecosystem services, restoration and reintroduction strategies.
4.3.2 DPSIR causal chain of addressing socioecological disturbances

The right-to-left DPSIR model (Fig. 5a) shows how the response within the model is undertaken. There is a double-headed arrow between the anthrodrivers and pressure at the top-right corner of the framework. Whenever the anthro-drivers cause real negative change on the state of ecological structures and processes, pressure is exerted on the entire system. In situations where either the ecodrivers or anthro-drivers have contributed to the reduction of CES flow and human wellbeing, the responsibility of initiating the necessary response and remedial changes lies with the stakeholder groups and institutions. The stakeholders have the pressure to act collectively for a unified cause to address the impacts on the cultural ecosystem services flow. In order to do so, the stakeholder groups and institutions have to target the entire society. This means that understanding the state of societal benefits and wellbeing is vital in explaining their connection to the quantity and quality of cultural ecosystem services. At this point, the society becomes aware of practical measures they need to undertake in restoration of both the ecological structures and processes and the potential suitable landscape types and human inputs for purposes of ensuring a sustainable flow of CES. 


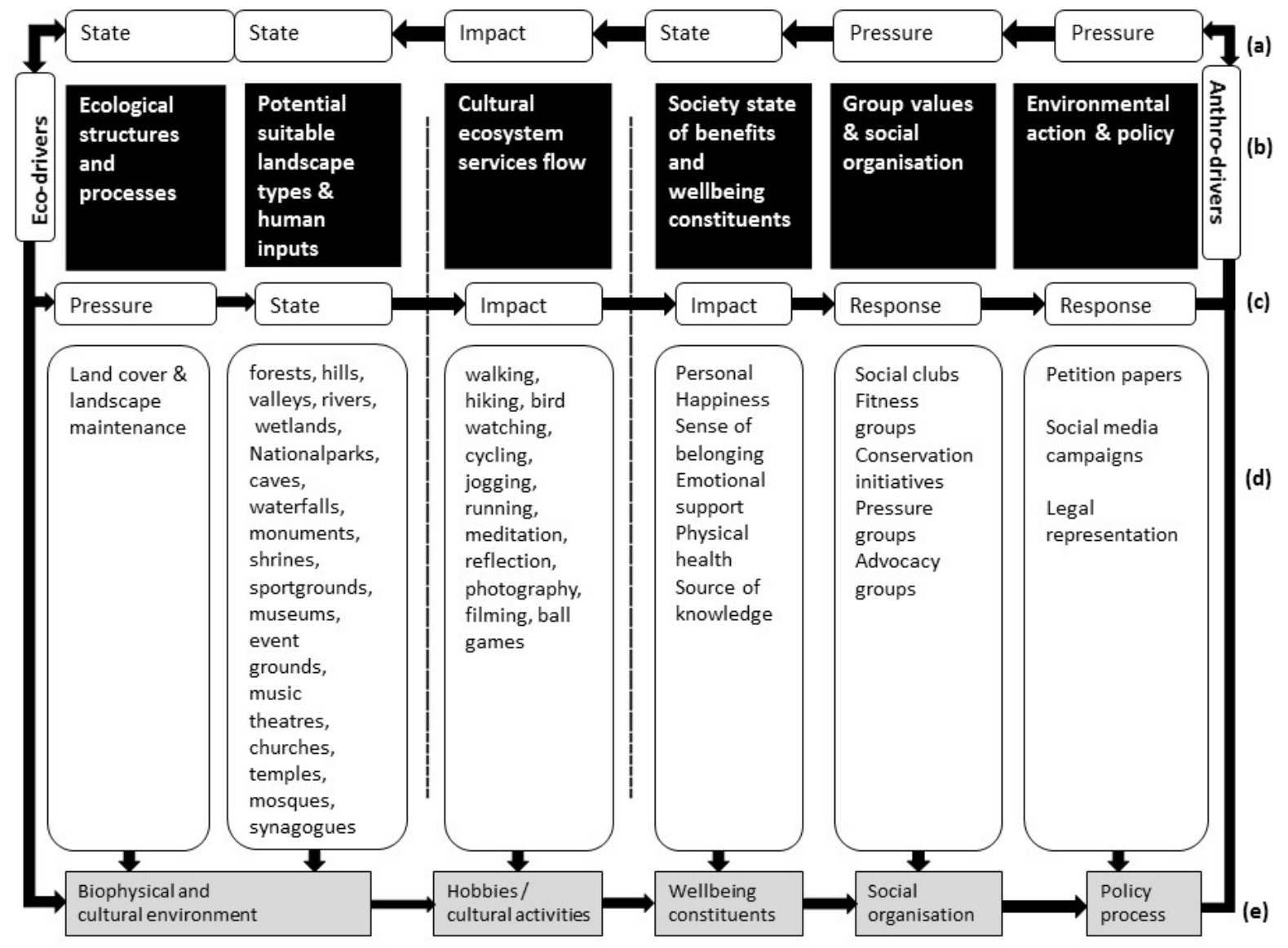

Figure 5: Connectivity between cultural ecosystem services (tourism and recreation) and wellbeing and integrating the connectivity to the 'ES cascade' and the DPSIR model $(n=24)$. Part (a) is the right-left flow DPSIR model; $(b)$ the extended ES cascade based on ecosystem theories to accommodate human wellbeing, which is based on social theories; (c) left-right flow DPSIR model; (d) practical definitions of part (b) using literature and case study data; (e) composite terminology for transparently communicating content of part (d).

\section{Discussion}

T ransparency and comprehensibility of CES indicators is vital whenever local people want to prioritize the most important CES at the local scale. This supports the described advantages of the qualitative method of prioritizing CES and their benefits (Chan et al. 2012). Uncertainties and ambiguities surrounding certain terms were found to be the main hindrances to CES indicator transparency. The ranking exercises revealed the importance of normative processes in subjective human wellbeing, which in essence show the participatory process in practice as proposed by Potschin et al. (2016). Freedom of choices and actions (MA 2005), which is anchored within the normative process, is thus an overarching constituent of human wellbeing reflected not only in other dimensions of wellbeing but also in priorities, values and preferences assigned to different CES by the local people.

Although the two indicators normatively selected to indicate each CES were assumed to differ insignificantly, the results showed that the overall mean score of some pairs of variables differed significantly. For example, hills/valleys and forests were selected as indicators of landscape aesthetics but the difference between their mean values was $30 \%$. Further statistics via the KMO and Bartlett's test confirm a high confidence level to the performed principal component analysis. Although there is high variability among the CES indicators, 32\% (lowest) to $67 \%$ (highest) variability of all the indicators is 
explained by the first principal component. With a loading of 0.90 , the importance of hills and valleys to human wellbeing in the study area can be estimated by the first principal component. The principal component analysis also revealed that museums and monuments tend to group together in indicating wellbeing. This is probably due to their strong ability in representing cultural identity of the people (Mazumdar \& Mazumdar 2004; Foxall 2013). Considering the highest weights for principal component one and two, components one seem to identify strongly with landscape aesthetics and naturalness, and component two seem to identify strongly with social, spiritual and mental tranquillity.

The importance of an indicator to measure human wellbeing showed to be dependent on the wellbeing constituent it was correlated to. This notwithstanding, it was interesting to note that 'worship places' were perceived to be more important for physical health than 'sport grounds'. This finding supports Margry's (2008) assertion that one purpose of undertaking a religious activity is to have physical healing. And because over $90 \%$ of Kenyans subscribe to a religious faith (www.africa. upenn.edu/NEH/kreligion.htm, 24.02.2017), it was a crucial variable in the study area and its role in promoting wellbeing was by chance expected to be high. However, it was not established whether the religious activities and physical health were directly or indirectly related to each other. Although religion and spirituality have been theoretically connected to wellbeing in literature (Biedenweg et al. 2014), their linkages to ES and wellbeing indicators have been demonstrated for the first time using this study.

The double-headed arrows in the framework for the inter-linkages between CES and human wellbeing within the DPSIR model, demonstrate the fact that at times the ecosystem could resist pressures originating from the drivers and hence its state remains uninterrupted. This demonstration invokes the theory of resistance, resilience and stability of ecosystems (Müller et al. 2010; Müller et al. 2016) and elevates a more compelling debate of the interlinkages between CES, wellbeing and the DPSIR model (a tripartite framework). Similarly, Nassl \& Löffler (2015) postulate that some changes caused by anthro-drivers do not reach thresholds capable of disrupting the ecological system. This means that the changes are manageable within the existing environmental action and policy framework. What is crucial to note from the ecosystem services cascade by Haines-Young \& Potschin (2010) is the elaborated nature of the process from biophysical structures and processes to the human benefits and values, as well as the process visualization provided by the DPSIR model (Müller \& Burkhard 2012) that starts with the drivers and ends with the responses. An additional level of detail has been provided by Fig. $5 a$. This is demonstrated by the process in which lobbying and advocacy is undertaken to formulate policy, and the existing social structures and institutions are used to create awareness to the public (consumers of cultural ecosystem services) for purposes of implementing the formulated policy in restoring and revitalizing the functional state of the ecosystem. It is only by closing the loops and interdependences that we can claim to adhere to the interdisciplinary strategies that integrate 'economic, social, cultural and ecological arguments' in environmental management (Müller et al. 2000).

Another key note is on how the boosted wellbeing of people is translating into social organisation and the environmental action and policy change. For example, in the case study, some visitors who ever benefitted from CES at the Karura forest are today organised as members of 'Friends of Karura Forest', who offer management and policy support for the forest. The sequential stages of an individual's dependence on the biophysical and cultural environment, creating relationships and ties with others, forming associations of common interests, concretizing the associations in the public domain and influencing environmental management policy tend to follow the socio-ecological model by the Centres for Disease Control and Prevention (CDC) (www.cdc.gov/cancer/crccp/sem.htm). However, this scenario of sequential transition from one stage to the other may not always be the same in other studies. There could be many reasons, especially in cases where local people do not pioneer such initiatives. Therefore, we present only a normative process in Fig. 5d (left to right), which should evolve to the last stage when all the necessary ingredients 
such as the freedom of association, the freedom of speech and right to petition are provided for and protected under the existing environmental law. It is then in order to propose that whenever the normative process does not flow to the final stage (environmental action and policy change), there is a fundamental ground to investigate the underlying pragmatic reasons. Moreover, since only $28 \%$ of ES studies investigate all the components of the ES cascade (Luederitz et al. 2015), our results offer special contribution and guidelines to bridge the gap through CES and wellbeing studies.

\subsection{Difficulties and uncertainties}

All ES studies are inherently complex due to the complexity of social-ecological systems and the interactions within them. These complexities together with several other issues (see list in Hou et al. 2013) lead to unavoidable difficulties and uncertainties of related studies. Some of them are discussed in the following.

\subsubsection{Sampling and time of conducting interviews}

Although the interviewees during piloting and actual interviews were selected non-discriminatively, the exercises were conducted in the daytime. Therefore, some residents with weekday work schedules incompatible with our interview hours for example, were naturally excluded from the exercise. However, our interviews were extended to weekends in order to ensure an equal chance for all residents to participate in the research.

\subsubsection{Subjective versus objective wellbeing}

By focusing on subjective human wellbeing on the local scale, it is unlikely that the results can easily be transferred to societal and national levels among people with different cultures. The process of assessing subjective wellbeing through individuals' responses is also not free from validity and accuracy issues (Diener \& Suh 1997). However, Diener and Suh (1997) intervened by saying that all processes (labelled 'objective' or 'subjective') of selecting any type of wellbeing indicators have a certain level of subjectivity. For example, social indicators are selected by a group of individual experts who use their experiential and judgemental wisdom to include or exclude certain indicators. This latter statement notwithstanding, we nevertheless recognize possibilities of uncertainties from such subjective processes. For example, subjective and survey responses are likely to contain biases such as the bandwagon effects (individual's response are influenced by thoughts and responses of other people), exposure effect (tendency to rate a CES indicator highly because of one's long exposure to it), anchoring bias (response based only on scanty pieces of information available to the respondent at the time of the interview) and the framing bias (influencing respondent's response by the way a question is constructed) (Steenbarger 2015).

5.1.3 Scale of wellbeing measurement and compatibility with multi-disciplinary studies

With the need to increase the number of multidisciplinary studies (Milcu et al. 2013), compatibility of scales and data for joint statistical and modelling operations are required. To meet compatibility requirements, further data aggregation might be demanded. This involves qualitative and quantitative data with varying degrees of sensitivity to certain statistical operations. For example, uncertainties could arise when trying to reconcile subjective, objective and empirical data values, and thus researchers should take precautions to avoid losing important details in the reconciliation process.

5.1.4 Results interpretation, reproducibility, comparability and reliability

Referring to our results, there should be no contention in the interpretation of results as far as the interpretation is done within the theoretical and conceptual frameworks of the ecosystem services cascade, human wellbeing and the DPSIR model. The commonly raised concern is on how to reproduce the results elsewhere, which has to do with the methodological process. Nevertheless, as far as this paper is concerned, methods are detailed to allow replication of such studies elsewhere. Our caution to researchers would rather point to the comparability of results in other studies even after applying the same methodology. This is because subjective wellbeing results should be specially handled on a 
case-by-case basis. Reliability of results in this study is high because the process of identifying, prioritizing and linking CES to wellbeing was under the control of local people and the resource management authorities in the area. Moreover, the statistical tests point to significant values and high confidence levels of the results.

\section{Conclusion}

$\mathrm{R}_{\mathrm{t} \text { ton }}$ eflecting our research questions, we can make the following conclusions:

How can the potential CES indicators in a study area be identified?

Cultural ecosystem services have a critical contribution to human wellbeing. However, when focusing on subjective wellbeing of people in a local study area, an all-inclusive process of identifying, validating and prioritizing cultural ecosystem services should be adopted. It is noteworthy that prior analyses of literature and site conditions set the stage for community participation. However, until validation and ranking of CES is done, the list of CES remains amorphous and irrelevant.

How can the potential CES indicators be socially, culturally and psychologically qualified?

Qualification of CES depends on a set of standards defined by an individual or society. Individuals use their experiences and socio-cultural value systems to guide their choices and actions. This means that subjective feedbacks are to a greater extent a reflection of social and cultural relations, networks and institutions. The quality of a CES depends on the real or perceived value or contribution to the wellbeing of an individual or society. The subjective method of qualifying CES is highly flexible and the modifications of indicator sets could be timely done to increase sensitivity to the social and cultural setting in a locality. The CES indicators show overlaps and positive correlations with each other. Some indicators have equal contributions (same mean value) to a certain wellbeing constituent. Religious and spirituality indicators of CES correlated strongly with all of the selected constituents of subjective wellbeing. It is in order to state that religion and spirituality are important in promoting wellbeing to a majority of the local people. It turned out that, for instance, hills and valleys were not good indicators for landscape aesthetics, at least for the study area.

\section{How are the CES and human wellbeing interconnected?}

It was observed that there is a connection between CES and human wellbeing. The means through which the connections emerge is demonstrable through community participation in CES and the wellbeing indicator identification process, eliciting of CES flows to people in real time and assessment of the impact on subjective wellbeing.

How are the interconnectivities integrated in the DPSIR model and what is the communication to the local people, decision-makers and ES research community?

The tripartite (CES-human wellbeing-DPSIR) framework has revealed that CES supply could be impacted by both eco- and anthro-drivers when the ecosystem cannot absorb the generated pressures, CES utilisation by humans does not observe minimum standards, and when the policy interventions do not curtail escalation of the impacts. Although the freedom of choice is seemingly passive in the debate of constituents of wellbeing, it is fundamental in the identification of CES and wellbeing indicators by the local people and experts. In addition to the existing 'ecosystem service cascade', the tripartite framework has displayed the full array of an environmental policy -from formulation to implementation stage. The confirmed benefits to human wellbeing is a boost to ES research because it increases its accountability and prove of the wide spectrum of benefits from ecosystems to humans. Similarly, an improved human wellbeing can result into an active civil society that informs environmental policy and decision-making. Therefore, the tripartite framework opens more possibilities and opportunities from which ES research and environmental policy could reinforce one another. 


\section{Acknowledgement}

T his work is part of a PhD project funded by the Catholic Academic Exchange Service (KAAD) organization in Germany. We thank Friends of Karura Forest (FKF), Kenya Forest Service (KFS), Surveys of Kenya, and the Regional Centre for Mapping of Resources for Development (RCMRD) for their cooperation and contribution during the research. We specially thank our colleagues in the Department of Ecosystem Management, Kiel University. We sincerely thank the anonymous interviewees and experts who dedicated their time to participate in the piloting and interview sessions. Finally, we thank the editorial team of the Journal Landscape Online and the anonymous reviewers for their constructive comments that highly improved the quality of this article.

\section{References}

Abunge, C.; Coulthard, S. \& Daw, T.M. 2013. Connecting marine ecosystem services to human well-being: Insights from participatory well-being assessment in Kenya. Ambio 42(8), 1010-1021. http://doi.org/10.1007/s13280-013-0456-9

Alderman, D.H. \& Dwyer, O.J. 2009. Memorials and Monuments. International Encyclopedia of Human Geography, 51-58.

Alkire, S. 2002. Dimensions of human development. World Development 30 (2), 181-205. http:// dx.doi.org/10.1016/S0305-750X(01)00109-7

Alkire, S.; Dercon, S .; Foster, J.; Klugman, J. ; Santos, M. E. ; \& Yalonetzky, G. 2011. Multidimensional Poverty and its Discontents. Oxford Poverty and Human Development Initiative Working Paper No. 46,University of Oxford 46, 1-23. http:// dx.doi.org/10.2139/ssrn.2118543
Biedenweg, K.; Hanein, A.; Nelson, K.; Stiles, K.; Wellman, K.; Julie Horowitz, J. \& Vynne, S. 2014. Developing Human Wellbeing Indicators in the Puget Sound: Focusing on the Watershed Scale, Coastal Management, 42:4, 374-390, DOI:10.108 0/08920753.2014.923136. http://dx.doi.org/10. 1080/08920753.2014.923136

Bérenger, V. \& Verdier-Chouchane, A. 2007. Multidimensional Measures of Well-Being: Standard of Living and Quality of Life Across Countries. World Development 35(7), 1259-1276. http://doi.org/10.1016/j.worlddev.2006.10.011

BIP 2011. Guidance for national biodiversity indicator development and use. UNEP World Conservation Monitoring Centre, Cambridge, UK. 40pp.

Brida, J.G.; Disegna, M. \& Scuderi, R. 2013. Expert Systems with Applications Visitors of two types of museums : A segmentation study. Expert Systems With Applications 40(6), 2224-2232. http:// dx.doi.org/10.1016/j.eswa.2012.10.039

Brown, C.; Reyers, B.; Ingwall-King, L.; Mapendembe, A.; Nel, J.; O'Farrell, P.; Dixon, M. \& BowlesNewark, N.J. 2014. Measuring ecosystem services: Guidance on developing ecosystem service indicators. UNEP-WCMC, Cambridge, UK.

Burgess, E.W. 1954. Social relations, activities, and personal adjustment. American Journal of Sociology 59(4), 352-360. http://www. journals.uchicago.edu/doi/abs/10.1086/221368 (24.02.17).

Burkhard B, \& Müller, F. 2008. Driver-pressurestate-impact-response. In: Jørgensen SE, Fath $B D$, editors. Ecological indicators. Vol. [2] of Encyclopedia of Ecology Oxford: Elsevier, 967-70.

Canaviri, J.A. 2016. Measuring the concept of "wellbeing": A first approach for Bolivia. International Journal of Wellbeing, 6, 36-80. http://dx.doi.org/10.5502/ijw.v6i1.363 
Chan, K.M.A.; Satter, T. \& Goldstein, J. 2012. Rethinking ecosystem services to better address and navigate cultural values, Ecological Economics,74, 8-18. http://doi.org/10.1016/j. ecolecon.2011.11.011

Chiesura, A. 2004. The role of urban parks for the sustainable city. Landscape and urban planning, 68(1), 129-138. http://dx.doi.org/10.1016/j. landurbplan.2003.08.003

Costanza, R.; Arge, R.; De Groot, R. ; Farberk, S.; Grasso, M.; Hannon, B.; Limburg, K.; Naeem, S.; O’Neill, R.; Paruelo, J.; Raskin, R.; Suttonkk, P. \& Suttonkk, P. 1997. The value of the world' s ecosystem services and natural capital. Nature, 387(May), 253-260. http://doi.org/10.1038/387253a0

Daniel, T. C.; Muhar, A.; Arnberger, A.; Aznar, O.; Boyd, J. W.; Chan, K.; Costanza, R.; Elmqvist, T.; Flint, C.; Gobster, P.; Grêt-Regamey, A.; Lave, R.; Muhar, S.; Penker, M.; Ribe, R.; Schauppenlehner, T.; Sikor, T.; Soloviy, I.; Spierenburg, M.; Taczanowska, K.; Tam, J. \& von der Dunk, A. 2012. Contributions of cultural services to the ecosystem services agenda. Proceedings of the National Academy of Sciences, 109(23), 8812-8819. http://doi. org/10.1073/pnas.1114773109

Darvill, R. \& Lindo, Z. 2015. Quantifying and mapping ecosystem service use across stakeholder groups : Implications for conservation with priorities for cultural values. Ecosystem Services, 13, 153-161. http://doi.org/10.1016/j.ecoser.2014.10.004

De Groot, R.S.; Alkemade, R.; Braat, L.; Hein, L. \& Willemen, L. 2010. Challenges in integrating the concept of ecosystem services and values in landscape planning, management and decision making. Ecological Complexity, 7(3), 260-272. http://doi.org/10.1016/j.ecocom.2009.10.006

Diener, E.D. \& Suh, E. 1997. Measuring quality of life: economic, social, and subjective indicators. Social Indicator Research, 40, 189-216. doi:10.1023/A:1006859511756. http://link. springer.com/article/10.1023/A:1006859511756
Dobbs, C:, Escobedo, F.J \& Zipperer, W.C. 2011. A framework for developing urban forest ecosystem services and goods indicators. Landscape Urban Plan 99:196-206. http://dx.doi.org/10.1016/j. landurbplan.2010.11.004

Dodge, R.; Daly, A. P.; Huyton, J. \& Sanders, L.D. 2012. The challenge of defining wellbeing. International Journal of Wellbeing, 2, 222-235. http://doi.org/10.5502/ijw.v2i3.4. http://www. internationaljournalofwellbeing.org/index.php/ ijow/article/view/89 (24.02.2017).

Duraiappah, A.K. 2002. Poverty and ecosystems: a conceptual framework. UNEP Division of Policy and Law Paper. UNEP Nairobi. 49pp. (24.02.2017).

FAO 2016. Global forest resources assessment 2015: How are the world's forests changing? http:// www.fao.org/3/a-i4793e.pdf (24.02.2017).

Feld, C.K.; Martins, P.; Sousa, P.; De Bello, F.; Bugter, R.; Grandin, U.; Hering, D.; Lavorel, S.; Mountford, O.; Pardo, I.; Pärtel, M.; Römbke, J.; Sandin, L.; Jones, B.K. \& Harrison, P. 2009. Indicators of biodiversity and ecosystem services : a synthesis across ecosystems and spatial scales. Oikos 118, 1862-1871. http://doi.org/10.1111/j.16000706.2009.17860.x

Foxall, A. 2013. Communist and Post-Communist Studies A contested landscape: Monuments, public memory, and post-Soviet identity in Stavropol', Russia. Communist and PostCommunist Studies 46(1), 167-178. http://doi. org/10.1016/j.postcomstud.2012.12.012

Francis, J.; Giles-Corti, B.; Wood, L. \& Knuiman, M. 2012. Creating sense of community: The role of public space. Journal of Environmental Psychology, 32(4), 401-409. http://doi.org/10.1016/j. jenvp.2012.07.002 
Frew, E.J.; Wolstenholme, J.L. \& Whynes, D.K. 2004. Comparing willingness-to-pay: bidding game format versus open-ended and payment scale formats. Health Policy 68 (3), 289-298. http:// dx.doi.org/10.1016/j.healthpol.2003.10.003

Gee, K. \& Burkhard, B. 2010. Cultural ecosystem services in the context of offshore wind farming: A case study from the west coast of SchleswigHolstein. Ecological Complexity 7(3), 349-358. http://doi.org/10.1016/j.ecocom.2010.02.008

Haines-Young, R.\& Potschin, M. 2010. The links between biodiversity, ecosystem services and human well-being. Ecosystem Ecology: A New Synthesis, 110 - 139. http://doi.org/10.1017/ CBO9780511750458.007

Harrison, F.; Van Sluijs, E. M. F.; Corder, K. \& Jones, A. 2016. Health \& Place School grounds and physical activity: Associations at secondary schools, and over the transition from primary to secondary schools 39, 34-42. http://doi.org/10.1016/j. healthplace.2016.02.004

Headey, B.W. \& Wearing, A.J. (eds.) 1992. Understanding happiness: A theory of subjective well-being. Longman Cheshire, Melbourne.

Hernández-Morcillo, M.; Plieninger, T. \& Bieling, C. 2013. An empirical review of cultural ecosystem service indicators. Ecological Indicators 29, 434-444. http://doi.org/10.1016/j. ecolind.2013.01.013

Herzlich, C. 1973. Health and Illness - A social psychological analysis. Academic Press, London.

Hou, Y.; Burkhard, B., \& Müller, F. (2013). Uncertainties in landscape analysis and ecosystem service assessment. Journal of Environmental Management, 127, 117-131. http://dx.doi. org/10.1016/j.jenvman.2012.12.002
Kandziora, M.; Burkhard, B. \& Müller, F. 2013. Interactions of ecosystem properties, ecosystem integrity and ecosystem service indicators: A theoretical matrix exercise. Ecological Indicators 28, 54-78. http://doi.org/10.1016/j. ecolind.2012.09.006

K'Akumu, O. A. \& Olima, W. H. A. 2007. The dynamics and implications of residential segregation in Nairobi. Habitat International, 31(1), 87-99. http://doi.org/10.1016/j.habitatint.2006.04.005

La Rosa, D.; Spyra, M. \& Inostroza, L. 2015. Indicators of Cultural Ecosystem Services for urban planning: A review. Ecological Indicators. http://doi. org/10.1016/j.ecolind.2015.04.028

Luederitz, C.; Brink, E.; Gralla, F.; Hermelingmeier, V.; Meyer, M.; Niven, L.; Panzer, L.; Partelow, S.; Rau, A.; Sasaki, R.; Abson, D.; Lang, D.; Wamsler, C. \& Wehrden, H. 2015. A review of urban ecosystem services: six key challenges for future research. Ecosystem Services 14, 98-112. http://dx.doi. org/10.1016/j.ecoser.2015.05.001

MA (Millennium Ecosystem Assessment), 2005. Ecosystems and Human Well-being: Synthesis. Island Press/World Resources Institute, Washington DC.

Makachia, P. A. (2011). Evolution of urban housing strategies and dweller-initiated transformations in Nairobi. City, Culture and Society, 2(4), 219234. http://doi.org/10.1016/j.ccs.2011.11.001

Malik, Khalid. Human Development Report 2013. The Rise of the South: Human Progress in a Diverse World (March 15, 2013). http://ssrn.com/ abstract=2294673 (24.02.2017).

Margry, P. J. 2008. Shrines and pilgrimages in the modern world: New itineraries into the sacred. Amsterdam University Press, Amsterdam. http:// www.oapen.org/record/340101 (24.02.2017). 
Mascarenhas, A.; Ramos, T. B.; Haase, D. \& Santos, R. 2016. Participatory selection of ecosystem services for spatial planning: Insights from the Lisbon Metropolitan Area, Portugal. Ecosystem Services 18, 87-99. http://doi.org/10.1016/j. ecoser.2016.02.011

Mazumdar, S. \& Mazumdar, S. 2004. Religion and place attachment: A study of sacred places. Journal of Environmental Psychology 24(3), 385397. http://doi.org/10.1016/j.jenvp.2004.08.005

Metzger, M. J.; Rounsevell, M. D. A.; Reemans, R.; Acosta-michlik, L. \& Schröter, D. 2006. The vulnerability of ecosystem services to land use change. Agriculture, Ecosystems \& Environment 114, 69-85. http://doi.org/10.1016/j. agee.2005.11.025

Milcu, A. I.; Hanspach, J.; Abson, D. \& Fischer, J. 2013. Cultural Ecosystem Services: A Literature Review and Prospects for Future Research. Ecology and Society 18(3). http://dx.doi.org/10.5751/ES05790-180344

Müller, F.; Hoffmann-Kroll, R. \& Wiggering, H. 2000. Indicating ecosystem integrity - theoretical concepts and environmental requirements. Ecological Modelling 130, 13-23. http://dx.doi. org/10.1016/S0304-3800(00)00210-6

Müller, F.; Bergmann, M.; Dannowski, R.; Dippner, J. W.; Gnauck, A.; Haase, P.; Jochimsen, M.; Kasprzak, P.; Kröncke, I.; Kümmerlin, R.; Küster, M.; Lischeid, G.; Meesenburg, H.; Merz, C.; Millat, G.; Müller, J.; Padisák, J.; Schimming, C.; Schubert, H.; Schult, M.; Selmeczy, G.; Shatwell, T. Stoll, S.; Schwabe, M.; Soltwedel, T.; Straile, D. \& Theuerkauf, M. 2016. Assessing resilience in long-term ecological data sets. Ecological Indicators 65, 10-43. http:// dx.doi.org/10.1016/j.ecolind.2015.10.066

Müller, F. \& Burkhard, B. 2012. The indicator side of ecosystem services. Ecosystem Services 1(1), 2630. http://doi.org/10.1016/j.ecoser.2012.06.001
Müller, F.; Burkhard, B. \& Kroll, F. 2010. Resilience, Integrity and Ecosystem Dynamics: Bridging Ecosystem Theory and Management 115, 221-242, 10.1007/9783-540-75761-0_14. http://link.springer.com/ chapter/10.1007/978-3-540-75761-0_14

Mundia, C. N. \& Aniya, M. 2005. Analysis of land use/ cover changes and urban expansion of Nairobi city using remote sensing and GIS. International Journal of Remote Sensing, 26(13), 2831-2849. http://dx.doi.org/10.1080/01431160500117865

Nassl, M. \& Löffler, J. 2015. Ecosystem services in coupled social - ecological systems : Closing the cycle of service provision and societal feedback. Ambio 44, 737-749. http://doi.org/10.1007/ s13280-015-0651-y

Neugarten, B. L.; Havighurst, R. \& Tobin, S. 1961. The measurement of life satisfaction. Journal of Gerontology 16, 134-143. http://dx.doi. org/10.1093/geronj/16.2.134

Niemeijer, D. \& De Groot, R.S. 2008. A conceptual framework for selecting environmental indicator sets. Ecological Indicators, 8(1), 14-25. http://doi. org/10.1016/j.ecolind.2006.11.012

Petty, N. J.; Thomson, O. P. \& Stew, G. 2012. Ready for a paradigm shift? Part 2: Introducing qualitative research methodologies and methods. Manual Therapy 17(5), 378-384. http://doi. org/10.1016/j.math.2012.03.004

Plieninger, T.; Dijks, S.; Oteros-Rozas, E. \& Bieling, C. 2013. Assessing, mapping, and quantifying cultural ecosystem services at community level. Land Use Policy 33, 118-129. http://doi. org/10.1016/j.landusepol.2012.12.013

Potschin, M.; Haines-Young, R.; Fish, R. \& Turner, K.R. (eds.) 2016. Routledge handbook of ecosystem services. Routledge, New York. 
Ryff, C. D. 1989. Happiness Is Everything, or is it ? Explorations on the Meaning of Psychological Well-Being. Journal of Personality and Social Psyschology 57(6), 1069-1081. http://dx.doi. org/10.1037/0022-3514.57.6.1069

Sagie, H.; Morris, A.; Rofè, Y.; Orenstein, D.E. \& Groner, E. 2013. Cross-cultural perceptions of ecosystem services: A social inquiry on both sides of the IsraeliJordanian border of the Southern Arava Valley Desert. Journal of Arid Environments 97, 38-48. http://doi.org/10.1016/j.jaridenv.2013.05.007

Sainani, K.L. 2014. Introduction to principal components analysis. PM\&R, 6(3), 275-278. http://dx.doi.org/10.1016/j.pmrj.2014.02.001

Saisana, M. \& Philippas, D. (eds.) 2012. Sustainable Society Index (SSI): Taking societies' pulse along social, environmental and economic issues. European Union. http://composite-indicators.jrc. ec.europa.eu/. doi: 10.2788/6330 (24.03.2017).

Seligman, M.E.P. 2002a. Authentic happiness: Using the new positive psychology to realize your potential for lasting fulfilment. Nicholas Brealey Publishing, London.

Seligman, M. E. P. (ed.) 2011. Flourish - A new understanding of happiness and well-being - and how to achieve them. Nicholas Brealey Publishing, London.

Shin, D. \& Johnson, D. 1978. Avowed happiness as an overall assessment of the quality of life. Social Indicators Research 5(1), 475-492. http://dx.doi. org/10.1007/BF00352944

Spanò, M.; Gentile, F.; Davies, C. \& Lafortezza, R. 2017. The DPSIR framework in support of green infrastructure planning: A case study in Southern Italy. Land Use Policy, 61, 242-250. http://dx.doi. org/10.1016/j.landusepol.2016.10.051
SSI 2014. Sustainable Society Index. http://www. ssfindex.com/ssi2014/wp-content/uploads/pdf/ SSI2014.pdf (24.03.2017).

Steenbarger, B.N. (ed.) 2015. Trading Psychology 2.0: From best practices to best processes. John Wiley \& Sons, New York.

Stone, L.; Gabric, A. \& Berman, T. 1996. Ecosystem Resilience, Stability, and Productivity: Seeking a Relationship. The American Naturalist 148 (5), 892-903. http://www.journals.uchicago.edu/doi/ abs/10.1086/285961

Tenerelli, P.; Demsar, U. \& Luque, S. 2016. Crowdsourcing indicators for cultural ecosystem services: A geographically weighted approach for mountain landscapes. Ecological Indicators 64, 237-248. http://dx.doi.org/10.1016/j. ecolind.2015.12.042

Thieme, T. A. 2015. Turning hustlers into entrepreneurs, and social needs into market demands: Corporate-community encounters in Nairobi, Kenya. Geoforum, 59, 228-239. http:// dx.doi.org/10.1016/j.geoforum.2014.11.010

Thompson, C. W. 2002. Urban open space in the 21st century. Landscape and urban planning, 60(2), 59-72. http://dx.doi.org/10.1016/S01692046(02)00059-2

Tratalos, J. A.; Haines-Young, R.; Potschin, M.; Fish, R. \& Church, A. 2016. Cultural ecosystem services in the UK: Lessons on designing indicators to inform management and policy. Ecological Indicators 61, 63-73. http://doi.org/10.1016/j. ecolind.2015.03.040

Turner, R. \& Daily, G. 2008. The Ecosystem Services Framework and Natural Capital Conservation. Environmental and Resource Economics 39(1), 25-35. http://link.springer.com/article/10.1007/ s10640-007-9176-6 
UNEP-WCMC 2009. Report from the workshop on Ecosystem Service Indicators: "Developing and mainstreaming ecosystem service indicators for human wellbeing: Gaps, opportunities and next steps". (September), 1-33. http://old.unepwcmc. org/medialibrary/2010/10/31/2e08c7fd/ EcosystemServicelndicators_Workshop_Report_ Final.pdf (24.02.2017).

WB 2016. World Development Indicators: featuring the Sustainable Development Goals. http:// databank.worldbank.org/data/download/sitecontent/wdi-2016-highlights-featuring-sdgsbooklet.pdf (24.02.2017).

Weidenhammer, E. \& Gross, A. 2013. Museums and scientific material culture at the University of Toronto. Studies in History and Philosophy of Science 44(4), 725-734. http://dx.doi. org/10.1016/j.shpsa.2013.07.015

WHO 1997. WHOQOL Measuring Quality of Life. Geneva: World Health Organisation. http:// www.who.int/mental_health/media/68.pdf (24.02.2017)

Willemen, L.; Verburg, P. H.; Hein, L. \& van Mensvoort, M.E.F. 2008. Landscape and Urban Planning Spatial characterization of landscape functions. Landscape and Urban Planning 88, 34-43. http:// doi.org/10.1016/j.landurbplan.2008.08.004

Younan, S. \& Treadaway, C. 2015. Digital 3D models of heritage artefacts: Towards a digital dream space. Digital Applications in Archaeology and Cultural Heritage 2(4), 240-247. http://dx.doi. org/10.1016/j.daach.2015.11.001 